\title{
Plant Peptides (NCRs) and Plant Immunity Play Vital Roles in Determining Specificity Between Alfalfa Cultivars and Sinorhizobium Meliloti Strain
}

\section{Wenjuan Kang}

Gansu Agricultural University

\section{Xiaolong Li}

Gansu Agricultural University

Xiaoyan Zhang

Gansu Agricultural University

Shangli Shi ( $D$ 1103683808@qq.com )

Gansu Agricultural University

\section{Research Article}

Keywords: Alfalfa cultivar, Sinorhizobium meliloti, Symbiotic specificity, NCRs, Plant immunity, RNA-seq

Posted Date: November 12th, 2021

DOI: https://doi.org/10.21203/rs.3.rs-1043144/v1

License: (c) This work is licensed under a Creative Commons Attribution 4.0 International License. Read Full License 


\section{Abstract}

Alfalfa expresses significantly distinct sets of genes in response to infection by different rhizobia strains at the below-species level (i.e., biotype or strain). However, differences in the transcriptomic profiles of two alfalfa cultivars nodulated by a single rhizobium strain have been largely unexamined. In this study, the comparative RNA-seq analysis of two alfalfa cultivars, Medicago sativa cv. Gannong No. 3 and Gannong No. 9 inoculated with one Sinorhizobium meliloti strain LL2, with varying in symbiotic performance, was conducted, followed by a hub gene interaction network construction based on weighted gene co-expression network analysis (WGCNA). The G9-LL2 symbiotic system showed better nodule-formation, nitrogen-fixing, and growth characteristics than the G3-LL2 system. Compared with the uninoculated control (CK), the LL2-inoculated G9 plants (10053) produced more differentially expressed genes (DEGs) than the LL2-inoculated G3 plants (7112). A group of 227 (2623 shared) genes displayed completely distinguished expression in G9 $\left(6.63<\log _{2}(\mathrm{FC})<15.45\right)$ and $\mathrm{G} 3\left(-3.05<\log _{2}(\mathrm{FC})<12.05\right)$, which are primarily involved in encoding nodule-specific cysteine-rich peptides (NCRs), nodulin, and leghemoglobin. Although genes with predicted roles in nitrogen metabolism were primarily upregulated, and almost all of those in ubiquitin-mediated proteolysis and plant-pathogen interaction were suppressed, interestingly, a consistently higher expression level measured by $\log _{2}(\mathrm{FC})$ was observed in G9 plants. Hub gene interaction networks showed that the NCRs, late nodulin, and genes related to plant immunity (TIR-NBS-LRR, defensin, thioredoxin, thionine, and polygalacturonase) regulated other genes at the source node positions. After the successful initiation of nodulation in both alfalfa cultivars G3 and G9 by $S$. meliloti strain LL2, G9 achieved preferable outcomes of rhizobia-alfalfa symbiosis by equilibrating the antagonism and compatibility of plant immunity. It elevated PTI and suppressed defense and ETI, as well as enhancing nitrogen fixation and utilization efficiency by inducing the expression of genes encoding NCRs, nodulin, and leghemoglobin. Hub genes predominantly underlying the highly specific rhizobia-alfalfa symbiosis, positively governed by NCRs and fine-tuned immune antagonism, comprise NCRs, late nodulin, and TIR-NBS-LRR. These findings provide insights into the genetic mechanisms underlying the modification and efficient utilization of semi-compatible and incompatible rhizobia resources.

\section{Background}

Nitrogen has received special attention because of its importance in the vegetative and reproductive growth of plants (Thomas et al., 2019). As the most efficient nitrogen fixation system, Rhizobiumleguminous symbiosis exhibits not only excellent yield and quality effects, but also superior soil amelioration and ecological remediation functions. However, the performance of symbiotic systems between alfalfa (Medicago sativa L.) and rhizobia vary significantly among different alfalfa genotypes and rhizobium strains, reflecting a high degree of specificity at the genus, species, and even belowspecies level (i.e., biotype or strain) (Zhang et al., 2000; Kang et al., 2020). Symbiosis with high-efficiently nitrogen-fixing rhizobia strains is an essential strategy for the host plant to prevent rhizobia deception (Walker et al., 2020). This kind of specific selectivity permeates the whole process of symbiosis, with 
partner selection remaining during the nitrogen fixation stage (Walker et al., 2020). For example, $M$. laciniate and $M$. rigiduloides have been reported to establish efficient symbiotic systems with $S$. meliloti bv. Medicaginis and S. meliloti sv. rigiduloides (Perret et al., 2000).

Flavonoids produced by legume roots are key signals that respond to rhizobial nodule factors (NF). However, there is no consistent correlation between the flavonoids and the host range of rhizobia. From the rhizobia side, NF (Spaink, 2000), surface polysaccharides (Gage, 2004) and secreted proteins are known to alter Rhizobium-leguminous specificity (Walker et al., 2020). However, few reports are found concerning the specific molecular basis of efficient nitrogen-fixing process post nodule-formation, since counter-active measures between host and rhizobia can lead to incompatibility, even after the nodulation is successfully initiated (Roy et al., 2020; Walker et al., 2020). Therefore, there is a need to explore other key proteins and genes that determine the symbiotic specificity of different genotypes of alfalfa cultivars and rhizobia strains after the establishment of symbiosis.

Similar to the pathogenic specificity of pathogens, the specific symbiosis between rhizobia and alfalfa can initially stimulate the plant innate immunity response (Gourion et al., 2015), such as PAMP-triggered immunity (PTI), which helps in the selection of highly compatible rhizobia for symbiosis by excluding others found in alfalfa roots (Cyril et al., 2017). Resistance (R) genes possibly take responsibility for eliminating ineffective rhizobial strains by alfalfa (Reinhold-hurek et al., 2011; Wang et al., 2012). T3SS (type III secretion system) effector may also be sensed by R genes, mainly NBS-LRR and NB-ARC (Drogue et al., 2014; Zhang et al., 2016), to trigger effector-triggered immunity (ETI) regulating specific nodulation in host plants (Soto et al., 2009; Walker et al., 2020). For instance, the soybean NBS-LRR genes act as specificity determinants of host rhizobia by recognizing the effector proteins secreted by the rhizobial T3SS (Liu et al., 2014).

NCRs (nodule-specific cysteine-rich peptides) have antimicrobial properties in vitro, which confers protection to nodules by posing entry deterrence to undesirable microorganisms, while simultaneously preventing symbiont overgrowth (Willem et al., 2010; Alunni and Gourion, 2016). The genome of $M$. truncatula contains at least 700 genes encoding NCRs, which are highly expressed in nodules produced by $S$. meliloti infection and affect the nitrogen fixation process by regulating the terminal bacteriod differentiation (TBD) of $S$. meliloti strains (Wang et al., 2012). It is well established that NCRs positively regulate the effective symbiosis potentially through affecting partner compatibility (Roy et al., 2020; Walker et al., 2020). Diverse in their functions, action modes, and bacterial targets, NCRs determine the specificity of $M$. truncatula and $M$. sativa by optimizing the nitrogen supply process to host plants by excluding "parasitic" rhizobia in a strain-specific manner (Gergely and Éva, 2014; Sumitha et al., 2014; Wang et al., 2017; Kristina and Seyed, 2019; Lindström et al., 2019; Roy et al., 2020; Walker et al., 2020).

Second-generation sequencing is convenient for the profiling of the overall responses of plants to bacterial or fungal infections in some model plants (Larrainzar et al., 2015; Pérez-Montaño et al., 2016). RNA-seq transcriptomic analysis detects all differentially expressed genes (DEGs) in symbiotic relationships and has been used to research symbiotic characteristics, such as plant immunity (Nobori et 
al., 2018), plant hormone synthesis (Breakspear et al., 2014; Larrainzar et al., 2015; Van Zeijl et al., 2015; Jardinaud et al., 2016), and secondary metabolism (Huyghe et al., 2015; Paungfoo-Lonhienne et al., 2016; Powell and Doyle, 2017). Soybean (Glycine max) inoculated with two different genera of rhizobia, Bradyrhizobium japonicum and S. fredii (Yuan et al., 2016), were previously found to produce significantly different gene transcription patterns. Similarly, inoculation with compatible rhizobium strains did not stimulate the early defense response of Lotus japonicus, whereas incompatible and pathogenic rhizobia acted differently (Kelly et al., 2018).

Based on the significantly different symbiotic phenotypes of alfalfa cultivars M. sativa Gannong No. 9 and Gannong No. 3 plants caused by S. meliloti strain LL2 (Kang et al., 2020), in this study, their transcriptome profiles were examined prior to and after LL2 inoculation. The key processes and hub genes governing rhizobia-alfalfa specificity below the species level (e.g., cultivars and strains) were identified by comparing the specifically expressed genes. The resulting findings provide insights into the regulation of the interaction network between alfalfa and rhizobia, which is of great significance for accurately utilizing the yield increase effect of alfalfa -rhizobia symbiosis.

\section{Methods}

\section{Symbiotic performance of two alfalfa cultivars}

The seeds of alfalfa cultivars G9 and G3 were provided by the College of Pratacultural Science, Gansu Agricultural University. Strain LL2 (S. meliloti) was provided by the Key Laboratory of the Ministry of Education, Gansu Agricultural University.

The symbiotic performance of strain LL2 was determined in the two alfalfa cultivars. Briefly, the seeds were immersed in iodophor disinfectant $\left(2500 \mathrm{mg} \cdot \mathrm{mL}^{-1}\right.$ available iodine) for $5 \mathrm{~min}$, then in ST solution $(0.9 \% \mathrm{NaCl}$ and $0.5 \%$ Tween-80, v/v=1:1) for $1 \mathrm{~min}$, rinsed with sterile distilled water five times, and dried thoroughly. Secondly, the surface-sterilized seeds were sown with sterilized tweezers evenly onto autoclave sterilized sand (2-mm, $450 \mathrm{~g} / \mathrm{pot}$ ) in a plastic pot (width: $10 \mathrm{~cm}$, height: $13.2 \mathrm{~cm}$ ) at a depth of $2 \mathrm{~cm}$. Plastic basins $(29 \times 20 \times 9.5 \mathrm{~cm})$, each containing four pots and $500 \mathrm{~mL}$ of sterile distilled water, were then placed in an intelligent growth chamber (Siemens, Beijing, China), with the growth conditions set as described (Kang et al. 2020). The pots were irrigated with Hoagland nitrogen solution $(500 \mathrm{~mL})$ on day 7 , and 30 seedlings per pot were retained by thinning operation on day 10 .

Strain LL2 were cultured in TY broth medium (Beringer, 1974) on a rotary shaker $\left(28^{\circ} \mathrm{C}, 180 \mathrm{rpm}\right)$ for $18 \sim 24 \mathrm{~h}$, centrifuged $\left(25^{\circ} \mathrm{C}, 10000 \mathrm{rpm}\right.$ for $\left.10 \mathrm{~min}\right)$ and resuspended in sterilized distilled water to $\mathrm{OD}_{600}=0.5 \sim 1.0$ (Miao et al., 2017). The seedlings of cultivars $\mathrm{G} 9$ and $\mathrm{G} 3$ were inoculated with LL2 suspension ( $1 \mathrm{~mL}$ per seedling) on day 15 , with sterilized water irrigation used as the uninoculated control (CK). Each treatment was set to four replicates (pots). The Hoagland $\mathrm{N}$-free nutrient solution (500 $\mathrm{mL}$, once a week) and sterile distilled water were supplemented duly for seedlings growth. At 45 days post inoculation (dpi), the nodule number, effective nodule weight (the weight of pink nodules), nodule 
diameter, nodule nitrogenase activity, compound leaf number, shoot height, root length, shoot and root $\mathrm{dry} /$ fresh weight, and crude protein content were measured using standard methods (Kang et al., 2018). Nodules were graded as previously described (Li et al., 2009).

\section{Nodule micrographs}

To obtain micrographs, fresh nodules were detached from plants at $35 \mathrm{dpi}$ and fixed with $50 \%$ formaldehyde-acetic acid-ethanol fixative (Labgic Technology Co., Ltd, Beijing) for more than $24 \mathrm{~h}$, and then trimmed and placed in a dehydration box for dehydration and wax leaching. After embedding in the embedding machine, the obtained tissue chip wax blocks were sectioned using a paraffin slicer. For light microscopy, semi-thin sections $(4 \mu \mathrm{m})$ were stained with toluidine blue (G1032; Servicebio, Wuhan, China) for $5 \mathrm{~min}$, followed by xylene (Servicebio, Wuhan, China) for $10 \mathrm{~min}$, and sealed with neutral gum at room temperature. After staining, the sections were viewed using scanning electron microscopy (SU8100; Hitachi, Beijing, China).

\section{RNA-seq analysis}

RNA-seq was performed for four treatments of the two alfalfa cultivars (G9 and G3), including each inoculated with strain LL2 (G9-LL2 and G3-LL2) and an uninoculated control (G9-CK and G3-CK) with three independent replicates (Figure 3a). Hair roots with nodules (hair roots without nodules for CK) were harvested $45 \mathrm{dpi}$ and frozen immediately in liquid nitrogen. Total RNA extraction was performed according to the manufacturer's protocol [EASYspin Plus Plant RNA Isolation kit (Aidlab, Beijing, China)]. RNA concentration quantification and RNA integrity determination were conducted using NanoDrop (NanoDrop Technologies, Inc.) and Agilent 2100 Bioanalyzer (Agilent Technologies, Inc.).

Sequence libraries were achieved following the manufacturer's directives [NEBNext ${ }^{\circledR}$ Ultra ${ }^{T M}$ RNA Library Prep Kit for Illumina ${ }^{\circledR}$ (NEB, Ipswich, MA, USA)]. After the enrichment of mRNA with oligo (dT)-attached magnetic beads, six bases of random hexamer primers and M-MuLV reverse transcriptase were utilized for synthesizing the first-strand cDNA. Subsequently, the second strand CDNA was synthesized using a buffer solution, DNA polymerase I, RNase $\mathrm{H}$, and dNTPs. The synthesized cDNA was then purified and eluted with a QiaQuick PCR kit (Borunlaite, Beijing, China) and EB buffer solution before repaired to blunt ends. After adenylation at the 3 '-ends and sequence adaptor ligation of the DNA fragments with a hairpin loop structure, 150 200 bp cDNA fragments were selected through the agarose gel electrophoresis.

Ultimately, PCR was conducted using universal PCR primers, Phusion High-Fidelity DNA polymerase, and index $(X)$ primers. Twelve cDNA libraries were totally sequenced on the Illumina NovaSeq 6000 platform served by Sagene Biotech Co., Ltd. (Guangzhou, China).

\section{Determination of differentially expressed genes (DEGs)}

Raw RNA-seq data were presented in fastq format and adapters and sequences of low quality were removed through FastQC (v0.11.5). The assembling of the high-quality clean reads was accomplished with Trinity (v2.2.0) software (Grabherr et al., 2011). Sequences were classified into different classes 
based on their similarities, with those beyond $95 \%$ belong to one class, and the longest one of each class was designated as the unigene in subsequent processing. The transcripts were taxonomically and functionally annotated using Blast+ (v2.4.0) for $\mathrm{Nr}$ (non-redundant protein sequences from $\mathrm{NCBI}$ ) and $\mathrm{COG} / \mathrm{KOG}$ (cluster of orthologous groups of proteins), KAAS for KEGG, and Blast2GO (v2.3.5) for GO. Genes were identified with an E-value of $10^{-5}$ against sequences deposited in the database.

RSEM software package v1.2.31 was used for mapping full-length reads to the reference unigenes ( $\mathrm{Li}$ and Dewey, 2011). EdgeR v3.14.0 was used for DEGs determination (Robinson et al., 2010; Wu and Nacu, 2010). Blast2GO (v2.3.5) and KEGG (http://www.expasy.org) (Minour et al., 2007) were adopted for GO and KEGG pathway enrichment of DEGs, respectively. Significantly enriched GO functions and KEGG pathways were identified with a hypergeometric test.

\section{Weighted genes co-expression and hub gene analysis (WGCNA)}

The WGCNA package of R 3.6.2 was utilized to analyze the co-expression network of weighted genes (Langfelder and Steve, 2008). Thresholds with variable coefficient $\geq 0.35$ were selected to cover all DEGs that responded to rhizobium-alfalfa cultivar specificity, and the non-weighted gene co-expression networks of different cultivars were predicted using the compiled data from the Gene Expression Atlas (MTGEA). The eigenvalue of each recognition module was calculated to test the correlation with the rhizobium-alfalfa specificity. Gene modules most related to symbiotic traits were determined and used for hub gene network construction in Cytoscape 3.6.1. The top ten hub nodes (genes) in each module were detected according to gene weights by 12 kinds of methods in CytoHubba Plug-in (Shannon et al., 2003), which were then evaluated by TOPSISI (Technique for Order Preference by Similarity to an Ideal Solution) in $\mathrm{R}$ 3.6.2.

\section{Quantitative real-time PCR (qRT-PCR)}

The total RNA prepared earlier was utilized to conduct $q$ RT-PCR by using $2 \times$ SYBR Green PCR Mastermix SR1110 (Solarbio, Beijing, China), with $\beta$-actin as an endogenous control. Sequences of the oligonucleotide primers are provided in Additional file 7. Three biological replicates for each sample were obtained, with three independent technical replicates for each biological replicate. Analysis of the qRTPCR data were conducted by using the $2^{-\Delta \Delta C T}$ methods (Livak and Schmittgen, 2001).

\section{Statistical analysis}

Statistical analysis of symbiotic parameters and gene expression data were performed using Prism version 8.0 (GraphPad Software Inc., San Diego, California, USA). Correlation analysis between indicators was performed using the pheatmap package in $\mathrm{R}$ 3.6.2.

\section{Results}


LL2 inoculation promoted nodule formation and plant growth in the two alfalfa cultivars (Figure 1 and Additional file 1) (Kang et al., 2020), presenting significantly different symbiotic performances between G3 and G9 $(P<0.05)$ (Figure 2). A higher nodule number per plant $(12.25,157.89 \%)$, nitrogenase activity $\left(47.39 \mu \mathrm{mol} \cdot \mathrm{g}^{-1} \cdot \mathrm{h}^{-1}, 2434.22 \%\right)$, crude protein content $(35.67 \%, 120.55 \%)$, shoot dry weight (428.70 mg, $162.99 \%)$, and root dry weight (79.03 mg, 68.98\%) was observed in LL2-inoculated G9 plants compared to LL2-inoculated G3 plants (Figure 2a), with every two parameters showing a high positive correlation $\left(0.86<R^{2}<0.98\right)$ (Additional file 2). A fully effective nodulation (darker pink) was also observed in G9 roots compared to $\mathrm{G} 3$ roots (Figure $2 \mathrm{~b}, \mathbf{2 c}$ ). Compared with uninoculated controls (CK), the growth rate of shoot dry weight and crude protein content in G9 plants upon LL2 inoculation (550.36\% and $178.3 \%$ ) significantly outperformed that in G3 (166.5\% and $16.2 \%$, respectively). G9 and LL2 symbiosis showed an overwhelming advantage in growth promotion effects compared to G3 and LL2 symbiosis (Figure 1). From the perspective of nodule micrographs (Figure 2), semithin sections stained with toluidine blue showed that, in comparison with G9 nodules (Figure $\mathbf{2 e}, \mathbf{2} \mathbf{g}, \mathbf{2} \mathbf{i}, \mathbf{2 k}$ ), the formation of an apical meristem and more uncolonized cells were observed on the G3 nodule (Figure 2d). Besides, rhizobia in G3 symbiosomes were released and degraded (Figure $2 f, 2 h$ ), and premature senescence was induced (Figure 2j).

\section{Transcriptome response of alfalfa cultivars to LL2 inoculation}

After sequencing the 12 cDNA libraries constructed using 12 biological replicates (Figure 3a), the generated 95,120 unigenes were utilized for similarity searching and function annotation against commonly used databases (Kang et al., 2020). More cellular components were revealed for the genes in G3 (CK vs. LL2), while those in G9 (CK vs. LL2) were predominantly annotated in molecular functions and biological processes (Additional file 3). Genes involved in the metabolism of carbohydrates and energy, as well as in environmental adaptation, were significantly enriched for G9 (CK vs. LL2) (Additional file 4).

DEGs were designated based on the criteria of $\left|\log _{2}(F C)\right| \geq 1$ and false discovery rate (FDR, corrected-p value) < 0.05 . DEGs between G9 and G3 (G9 vs. G3) caused by LL2 inoculation (12299) exceeded that in uninoculated controls (5412) by $127 \%$ (Figure $3 b$ ). DEGs were also generated for LL2-inoculated G9 and G3 plants relative to the uninoculated controls (Figure 3c). The results revealed markedly higher DEG numbers (10053) for G9 (CK vs. LL2) than G3 (CK vs. LL2) (7112).

To analyze the differences in gene expression between G9 and G3 cultivars after inoculation with strain LL2, the DEGs of G9 (CK vs. LL2) and G3 (CK vs. LL2) were compared. In total, 2623 (18\%) genes were shared by G9 and G3 (Figure 3d), with the most genes annotated as plant-pathogen interactions (Figure 3e). According to the heat map generated by the FPKM value (Figure 4a), 8.65\% (227) genes were highly expressed in the G9-LL2 treatment, indicating that these genes responded specifically to the symbiosis between cultivar G9 and strain LL2 (G9/LL2-SE). Comparatively, 2.74\% (72) genes were specifically expressed in G3 and LL2 symbiosis (G3/LL2-SE). The other three groups of genes were upregulated (LL2UR) and downregulated (LL2-DR) by inoculation with LL2 in both cultivars, accounting for $39.00 \%$ (1023) and $49.60 \%$ (1301) of the total shared genes, respectively. 


\section{Genes specifically expressed in G9-LL2 treatment (G9/LL2-SE)}

G9/LL2-SE genes displayed completely opposite patterns of expression in the two alfalfa cultivars compared with the uninoculated controls (CK), with $\log _{2}(F C)$ of the $G 3$ DEGs ranging from -3.05 to 12.05 and those of G9 from 6.63 to 15.45 (Figure 4b, Table 1, and Table 2). In terms of gene functions, approximately $41.85 \%$ (95/227) of the G9/LL2-SE genes were associated with the synthesis of plant peptides, including NCRs (87), GRPs (6), and LEED...PEED (2), while 10.7\% (8.37/227) encoded nodulins (late nodulin, MtN20, MtN29, and nodulin-25) and Leghemoglobin (Lb120-1) (Figure 4b, Table 1, and Table 2). Additionally, genes involved in plant-pathogen interactions, such as disease resistance protein TIR-NBS-LRR (Medsa073145), LRR receptor-like kinase (Medsa074340, Medsa073461), EF-hand pair protein (Medsa059113, Medsa045239), and wall-associated receptor kinase-like (WAKL)(Medsa041705), were also identified. These results indicate that strain LL2 significantly promoted the expression of genes related to plant immunity, symbiotic specificity, nodule formation, and nitrogen fixation in G9 alfalfa plants, but had a much weaker effect on the expression of these genes in G3 alfalfa plants. 
Table 1 Genes encoding plant peptides

\begin{tabular}{|c|c|c|c|c|c|c|c|}
\hline Gene ID & $\begin{array}{l}\text { G3®CK } \\
\text { vs. LL2》 }\end{array}$ & $\begin{array}{l}\text { G9هCK } \\
\text { vs. LL2】 }\end{array}$ & $\begin{array}{l}\text { Gene } \\
\text { name }\end{array}$ & Gene ID & $\begin{array}{l}\text { G3凶CK } \\
\text { vs. } \\
\text { LL2】 }\end{array}$ & $\begin{array}{l}\text { G9هCK } \\
\text { vs. LL2】 }\end{array}$ & $\begin{array}{l}\text { Gene } \\
\text { name }\end{array}$ \\
\hline Medsa007949 & 8.06 & 9.42 & NCR & Medsa067439 & 6.16 & 12.56 & NCR \\
\hline Medsa034346 & 7.72 & 11.46 & NCR & Medsa053992 & 11.65 & 13.51 & NCR \\
\hline Medsa006285 & 7.25 & 11.36 & NCR & Medsa052886 & 9.17 & 12.81 & NCR \\
\hline Medsa008690 & 7.33 & 9.87 & NCR & Medsa034923 & 7.38 & 10.62 & NCR \\
\hline Medsa008750 & 12.05 & 13.17 & NCR & Medsa014170 & 7.98 & 11.33 & NCR \\
\hline Medsa008753 & 7.52 & 11.04 & NCR & Medsa072326 & 8.22 & 10.75 & NCR \\
\hline Medsa014914 & 9.45 & 12.58 & NCR & Medsa058759 & 5.80 & 9.89 & NCR \\
\hline Medsa017210 & 7.14 & 9.85 & NCR & Medsa065129 & 8.09 & 10.82 & NCR \\
\hline Medsa018696 & 7.52 & 11.16 & NCR & Medsa020713 & 7.28 & 9.09 & NCR \\
\hline Medsa025640 & 9.42 & 11.74 & NCR & Medsa013683 & 9.26 & 11.00 & NCR \\
\hline Medsa062600 & 7.81 & 11.68 & NCR & Medsa059121 & 8.74 & 11.81 & NCR \\
\hline Medsa015258 & 8.65 & 11.46 & NCR & Medsa025432 & 8.89 & 14.21 & NCR \\
\hline Medsa027338 & 8.52 & 12.48 & NCR & Medsa042566 & 7.22 & 12.18 & NCR \\
\hline Medsa042120 & 7.56 & 9.83 & NCR & Medsa016684 & 8.20 & 11.66 & NCR \\
\hline Medsa042122 & 7.45 & 11.17 & NCR & Medsa046555 & 9.92 & 14.03 & NCR \\
\hline Medsa003710 & 6.40 & 12.94 & NCR & Medsa013145 & 8.58 & 11.07 & NCR \\
\hline Medsa004208 & 8.85 & 11.91 & NCR & Medsa029227 & 8.22 & 13.06 & NCR \\
\hline Medsa004447 & 10.56 & 13.34 & NCR & Medsa073965 & 7.28 & 10.26 & NCR \\
\hline Medsa005209 & 8.32 & 11.29 & NCR & Medsa013375 & 7.14 & 10.28 & NCR \\
\hline Medsa005296 & 10.90 & 13.00 & NCR & Medsa047816 & 7.53 & 13.48 & NCR \\
\hline Medsa008688 & 7.38 & 9.93 & NCR & Medsa009336 & 6.04 & 13.29 & NCR \\
\hline Medsa037942 & 7.78 & 13.81 & NCR & Medsa020210 & 8.24 & 10.90 & NCR \\
\hline Medsa003835 & 7.11 & 7.75 & $\mathrm{NCR}$ & Medsa056421 & 7.78 & 10.36 & NCR \\
\hline Medsa050029 & 7.11 & 10.76 & NCR & Medsa074839 & 8.19 & 11.36 & NCR \\
\hline
\end{tabular}


Table 1 Genes encoding plant peptides (Continued)

\begin{tabular}{|c|c|c|c|c|c|c|c|}
\hline Gene ID & $\begin{array}{l}\text { G3凶CK } \\
\text { vs. } \\
\text { LL2\ }\end{array}$ & $\begin{array}{l}\text { G9هCK } \\
\text { vs. LL2】 }\end{array}$ & $\begin{array}{l}\text { Gene } \\
\text { name }\end{array}$ & Gene ID & $\begin{array}{l}\text { G3囚CK } \\
\text { vs. } \\
\text { LL2】 }\end{array}$ & $\begin{array}{l}\text { G9هCK } \\
\text { vs. } \\
\text { LL2】 }\end{array}$ & Gene name \\
\hline Medsa059084 & 7.38 & 10.79 & NCR & Medsa018680 & 7.56 & 10.75 & NCR \\
\hline Medsa051057 & 7.30 & 9.39 & NCR & Medsa035859 & 9.98 & 12.94 & NCR \\
\hline Medsa075195 & 9.66 & 15.06 & NCR & Medsa035860 & 6.53 & 11.32 & NCR \\
\hline Medsa040313 & 7.38 & 11.21 & NCR & Medsa023637 & 7.11 & 8.94 & NCR \\
\hline Medsa077227 & 7.87 & 12.38 & NCR & Medsa031336 & 7.76 & 9.79 & NCR \\
\hline Medsa049223 & 9.76 & 13.24 & NCR & Medsa029073 & 5.89 & 13.29 & NCR \\
\hline Medsa042804 & 6.43 & 10.97 & NCR & Medsa035962 & 9.38 & 11.80 & NCR144 \\
\hline Medsa023746 & 6.28 & 12.32 & NCR & Medsa049393 & 7.87 & 11.32 & NCR189 \\
\hline Medsa018679 & 7.38 & 9.06 & NCR & Medsa036690 & 7.74 & 10.42 & NCR21 \\
\hline Medsa075863 & 8.38 & 11.53 & NCR & Medsa010846 & 7.78 & 10.82 & NCR266 \\
\hline Medsa031906 & 6.67 & 11.26 & NCR & Medsa039486 & 9.36 & 13.38 & NCR28 \\
\hline Medsa039722 & 6.75 & 12.44 & NCR & Medsa051372 & 7.66 & 11.06 & NCR313 \\
\hline Medsa064389 & 6.21 & 12.29 & NCR & Medsa014916 & 8.91 & 11.62 & NCR314 \\
\hline Medsa064384 & 6.89 & 14.10 & NCR & Medsa004893 & 8.83 & 13.53 & NCR329 \\
\hline Medsa055876 & 6.17 & 13.08 & NCR & Medsa030028 & 7.56 & 10.05 & NCR329 \\
\hline Medsa038861 & 7.68 & 10.66 & NCR & Medsa011487 & 7.70 & 10.06 & GRP \\
\hline Medsa035295 & 7.30 & 11.77 & NCR & Medsa039403 & 7.28 & 10.48 & GRP \\
\hline Medsa073125 & 6.92 & 10.78 & NCR & Medsa011488 & 6.77 & 13.33 & GRP \\
\hline Medsa027870 & 8.44 & 10.71 & NCR & Medsa036581 & 7.25 & 10.78 & GRP \\
\hline Medsa014478 & 7.97 & 10.05 & NCR & Medsa046950 & -3.05 & 6.63 & GRP \\
\hline Medsa028643 & 8.37 & 9.97 & NCR & Medsa023875 & 9.25 & 14.19 & GRP \\
\hline Medsa038994 & 7.80 & 12.23 & NCR & Medsa043118 & 7.92 & 8.75 & LEED...PEED \\
\hline Medsa083023 & 7.40 & 9.66 & NCR & Medsa043121 & 9.09 & 13.43 & LEED...PEED \\
\hline Medsa047245 & 8.86 & 12.37 & NCR & & & & \\
\hline
\end{tabular}

Note: Data are $\log _{2}$ (fold change) values for each differentially expressed gene. NCR, Nodule CysteineRich (NCR) secreted peptide; GRP, Nodule-specific Glycine Rich Peptide; LEED...PEED, leguminosin group 567 LEED...PEED secreted peptide. 
Table 2 Genes encoding nodulin and leghemoglobin

\begin{tabular}{|c|c|c|c|c|}
\hline Gene ID & & G3『CK vs. LL2】 & G9『CK vs. LL2】 & Gene name \\
\hline \multirow[t]{9}{*}{ Nodulin } & Medsa045712 & 8.12 & 9.02 & Late nodulin \\
\hline & Medsa028826 & 7.56 & 10.06 & Late nodulin \\
\hline & Medsa020398 & 7.11 & 11.27 & Late nodulin \\
\hline & Medsa055235 & 6.29 & 11.45 & Late nodulin \\
\hline & Medsa011901 & 6.02 & 9.16 & MtN20, partial \\
\hline & Medsa076847 & 6.39 & 10.74 & MtN26, partial \\
\hline & Medsa026013 & 8.00 & 11.43 & Nodulin-25 protein \\
\hline & Medsa062064 & 8.68 & 13.46 & Nodulin-25 protein \\
\hline & Medsa062065 & 9.91 & 11.99 & Nodulin-25 protein \\
\hline \multirow[t]{10}{*}{ Leghemoglobin } & Medsa068332 & 5.99 & 11.32 & Leghemoglobin \\
\hline & Medsa020389 & 11.31 & 14.15 & Leghemoglobin \\
\hline & Medsa020390 & 6.06 & 15.45 & Leghemoglobin \\
\hline & Medsa084770 & 3.70 & 13.54 & Leghemoglobin \\
\hline & Medsa015627 & 8.36 & 10.97 & Leghemoglobin Lb120-1 \\
\hline & Medsa015628 & 5.76 & 11.92 & Leghemoglobin Lb120-1 \\
\hline & Medsa086452 & 11.41 & 11.48 & Leghemoglobin Lb120-1 \\
\hline & Medsa042670 & 6.36 & 14.27 & Leghemoglobin Lb120-1 \\
\hline & Medsa068334 & 8.42 & 13.72 & Leghemoglobin, partial \\
\hline & Medsa025621 & 6.18 & 8.86 & Leghemoglobin-like \\
\hline
\end{tabular}

Note: Data are $\log _{2}$ (fold change) values for each differentially expressed gene.

\section{Genes specifically expressed in G3-LL2 treatment (G3/LL2-SE)}

Although the G3/LL2-SE genes showed the highest FPKM values in G3-LL2 treatment (Figure 4a), there were no significant differences in expression between $G 9$ and G3. All were upregulated $\left(\log _{2}(F C)>0\right)$, except for those involved in nucleotide excision repair, plant hormone signal transduction, membrane part, and protein processing in endoplasmic reticulum (Figure 4c). The G3/LL2-SE genes were mainly involved in the membrane part, ribosome, and catalytic/hydrolase synthesis, as well as in carbohydrate derivative binding (Figure 4c). Genes encoding BHLH transcription factors (Medsa060643, Medsa029746, 
and Medsa038664), LRR receptor-like kinase (Medsa089271 and Medsa031888), thioredoxin (Medsa023753), and disease resistance protein TIR-NBS-LRR (Medsa018881) were all upregulated (data not provided). Similar expression patterns of G3/LL2-SE genes in G9 and G3 indicated a weak correlation between these genes and the specificity between rhizobium strain LL2 and alfalfa cultivars in this study.

\section{Genes specifically regulated in both alfalfa cultivars upon LL2 inoculation (LL2-UR and LL2-DR)}

Except for the genes specifically expressed in G3-LL2 and G9-LL2 treatment, most of the genes (88.6\%) showed a highly consistent expression pattern in both G9 and G3 cultivars upon LL2 inoculation (Figure 4a). DEGs involved in all GO functions showed similar expression patterns in the two alfalfa cultivars (Additional file 5a). KEGG pathway annotation (Additional file 5b) showed that all genes encoding ribosomes, as well as most of the genes involved in amino acid synthesis, fatty acid metabolism, glycolysis, carbon metabolism, nitrogen metabolism, and flavonoid biosynthesis, were LL2-UR genes in alfalfa cultivars G9 and G3. For the LL2-DR genes, a large number of genes were associated with plantpathogen interactions and plant hormone signal metabolism.

It is worth noting that G9 plants showed almost consistently higher $\log _{2}(\mathrm{FC})$ values for genes, either LL2UR or LL2-DR, involved in nitrogen metabolism (except one gene encoding GLUL (Medsa033979)) (Figure 5a), ubiquitin-mediated proteolysis (except two genes encoding SIAH01 (Medsa083068) and Skp1 (Medsa 016789)) (Figure 6a), and plant-pathogen interaction (except four genes encoding HSP90 (Medsa088149, Medsa040257, and Medsa009558) and PR1 (Medsa075698)) (Figure 7a). The 12 genes encoding nitrate reductase NADH-like protein (NR), ferredoxin-nitrite reductase (NirA), carbonic anhydrase (CA), and high-affinity nitrate transporter (Nrt) in nitrogen metabolism displayed a higher potential for nitrogen utilization (Figure 5b). Genes play key roles in ubiquitin-mediated proteolysis (Figure $\mathbf{6 b}$ ) comprising alternative reading frame-beta-protein 1 (ARF-BP1), chitinase (Cull), F-box SKP2A-like protein (F-box), seven in absentia family protein (SIAH-1), S-phase kinase-associated protein 1 (Skp1), ubiquitinconjugating enzyme E2 (UBE2), and E3 ubiquitin-protein ligase (UBE3C). Among the genes related to PAMP-triggered immunity (Figure 7), calcium-binding protein (CaMCML), calcium-dependent protein kinase (CDPK), and respiratory burst oxidase-like protein (Rboh) were partially upregulated upon LL2 inoculation. Defense-related genes were also induced by LL2 inoculation, including flagellin sensing 2 (FLS2), MAP kinase kinase kinase-like protein (MEKK1), WRKY2553, and pathogenesis-related protein 1 (PR1). In contrast, the ETI-associated genes RPM1 (CC-NBS-LRR, LRR and NB-ARC, NB-ARC, NBS-LRR) and resistance to Pseudomonas syringae protein 2 (RPS2) were distinctively suppressed, except for heat shock cognate protein 90 (HSP90).

\section{Weighted gene co-expression network analysis (WGCNA)}

According to the expression pattern of genes related to two symbiotic parameters (shoot dry weight and root dry weight) and the pairwise correlation between genes, a co-expression network was established in which highly correlated genes were defined as modules, and each module could identify a set of genes. 
Forty-eight unique modules were identified by WGCNA, and the gene expression profile ID of each module represented its most significant component and feature. The resulting 48 features had different correlations with the two traits (Figure 8). Three co-expression modules, namely MEcoral 1, MEfloralwhite, and MElightsteel Blue 1, were composed of genes that were highly correlated with shoot and root dry weight $(R>0.5)$ (Figure 8), indicating that these genes are probably involved in altering plant yield and determining specificity.

\section{Hub gene interaction networks}

Hub genes not only act as important targets, but also regulate other genes in related pathways and play crucial roles in biological processes. Hub genes in each module were determined based on gene interaction networks (Figure 9), 12 types of CytoHubba methods (Additional file 6), and TOPSIS evaluations (Figure 10). Except for some unknown genes (Figure 9a), hub genes in the MElightSteel Blue 1 module comprised those encoding late nodulin, NCR, PIFI helicase, Actin, H+-ATPse, At3g27390, TIRNBS-LRR, and ubiquitin C. TIR-NBS-LRR (Medsa073145) and NCR (Medsa029073) regulated 21 and 18 other genes at the source node positions (Figure 9a). Ranked first in the MEfloralwhite module (Figure 9b), the transposon-encoding gene (Medsa087889) was found to have connectivity with 29 other genes, acting as a target for most of them. Four hub genes (TMV resistance protein N, BHLH122, HSP70, and NB-ACR) linked to plant-pathogen interactions were also observed in this module. Among the 38 hub genes detected in Module MEcoral 1 (Figure 9c), NCRs (15), nodulins (7), and plant immunity-related (6) genes made up the vast majority, and interacted with 473,68 , and 198 other genes by acting as a source and fewer target nodes, respectively (Figure 9c). Another group of genes encoding FK506, FRS5, RALF, apyrase, CDSL, PTK, ATF, OPT, H+-ATPase, ARP, and ERF003 were also identified as hub genes (Figure 9c).

\section{Validation of DEGs by $q R T-P C R$}

Primers were designed to verify the nine hub genes using qRT-PCR (Additional file 7). These genes are involved in encoding NCRs (Medsa029073, Medsa014916, Medsa030028, Medsa013375, and Medsa047816), TIR-NBS-LRR (Medsa073145), leghemoglobin (Medsa084770), late nodulin (Medsa045712), and MtN20 (Medsa011901). The qRT-PCR results were in agreement with the expectations derived from the RNA-seq data (Additional file 8).

\section{Discussion}

\section{Alfalfa cultivar G9 showed stronger symbiotic specificity with the rhizobium strain LL2}

After inoculation with strain LL2, G9 showed stronger nodule formation, nitrogen fixation, growth effects, and later nodule senescence than G3, exhibiting a high extent of symbiotic specificity between alfalfa cultivars G9 and LL2. When there is a strong alfalfa-rhizobia specificity, the rhizobium-inoculated alfalfa plants form effective nodules, fix nitrogen, and provide nitrogen nutrition for plant growth in an efficient "mutual benefit" manner, producing excellent symbiosis outcomes (Roy et al., 2020). In terms of weak 
specificity, rhizobium-inoculated alfalfa plants are: (1) incapable of nodule formation, (2) capable of forming nodules but only fixing a small amount of nitrogen, or (3) capable of forming nodules but fixing no nitrogen. In this case, the symbiosis balance favors the rhizobium strain, which consumes plant nutrients in a kind of "parasitic" manner, resulting in poor or even no promotion of plant growth (Schumpp and Deakin, 2010; Matthew et al., 2012). Although LL2-inoculated G3 plants formed nodules and yielded higher shoot (166.5\%) and root (319.46\%) dry matter than uninoculated G3 plants (G3-CK), the nodule number per plant and nodule nitrogenase activity were significantly lower than that of G9-LL2 treatment, leading to a markedly lower plant protein content (120.55\%). Compared with the nearly six times higher shoot dry weight increment (550.36\%) in cultivar G9 resulted from strain LL2, there was only a weak growth-promoting effect of strain LL2 on cultivar G3, similar to that in situation (2) above.

\section{Molecular bases for alfalfa cultivar-rhizobium strain specificity}

Legume plants are known to alter gene expression patterns via the infection and colonization of homologous rhizobia. However, the transcriptional response of different alfalfa cultivars of the same species to a single rhizobium strain has been scarcely reported (Kang et al., 2020). In this study, LL2 inoculation amplified the transcriptome expression differences (DEG numbers) between cultivars G9 and G3 by $127 \%$ (Figure $3 \mathbf{b}$ ), which was conducive to the location of genes specifically related to symbiosis in each cultivar. In terms of a single alfalfa cultivar, the DEG numbers in G9 (CK vs. LL2) were $41.35 \%$ higher than those in G3 (CK vs. LL2) (Figure 3b). G9 responded more sensitively to LL2 inoculation and its symbiotic related genes reacted much stronger at the transcriptome level; for example, a higher $\log _{2}(\mathrm{FC})$ value was observed for genes involved in nitrogen metabolism, ubiquitin-mediated proteolysis, and plantpathogen interaction. These results were in good agreement with the symbiotic performance of G9 upon LL2 inoculation.

\section{Potential roles of plant peptides NCRs, nodulin, and leghemoglobin in rhizobia-alfalfa specific interaction}

Symbiotic interactions of cultivars G9 and G3 with strain LL2 showed the same trend but varying degrees of gene expression patterns at the transcriptional level. For example, LL2 induced a much higher upregulation of genes encoding the synthesis of NCRs, GRPs, LEED...PEED, nodulins, and leghemoglobin in cultivar G9 compared to that in G3 plants. Studies have reported on the importance of NCRs, not only in their defensin-like capability of killing rhizobia (e.g., NFS1 and NFS2 in M. truncatula A17), but also their essential prerequisite for bacterial survival and differentiation (e.g., NCR169 and NCR211) (Willem et al., 2010; Roy et al., 2020). NCRs, together with plant peptide GRPs and LEED...PEED, play important roles in plant immunity, nitrogen fixation, and determination of host specificity (Attila et al., 2018). Under the absence or downregulation of particular NCRs, bacteria differentiate to some extent, but then die early in the symbiosome (Roy et al., 2020). Only the expression of appropriate NCRs and bacterial proteins can give rise to fully differentiated, $\mathrm{N}$-fixing sterile bacteroids (Roy et al., 2020). The reduced expression of NCRs here leads to an earlier release of bacteria from the in-symbiosome to the out-symbiosome and nodule senescence and a lower symbiotic outcome (Figure 2). Nodulins (mainly late nodulins) are crucial for nodule metabolism and function (Sánchez et al., 2011), and leghemoglobin ensures the normal 
function of nitrogen fixation in nodules (Burghardt et al., 2017). The upregulation of these genes in G9 plants resulted in a more successful establishment of specific rhizobia-alfalfa symbioses, and ultimately, a fine outcome of the nitrogen fixation symbiosis (Figure 11). Transcriptome results were confirmed by the high values of nodule number per plant, nitrogenase activity, crude protein content, and shoot and root dry weight in cultivar G9 upon LL2 inoculation.

\section{LL2 regulates specific expression of genes related to nitrogen metabolism in alfalfa cultivars}

All genes related to nitrogen metabolism, either upregulated or downregulated, showed a higher $\log _{2}(\mathrm{FC})$ value in G9 plants upon LL2 inoculation than in G3. Nrt can improve nitrate availability by assimilating $\mathrm{NO}^{3-}$ at very low external concentrations (Charrier et al., 2015). The enzymatic reduction of nitrate $\left(\mathrm{NO}^{3-}\right)$ to nitrite $\left(\mathrm{NO}^{2-}\right)$ by $\mathrm{NR}$ is critical for nitrogen acquisition in most plants (Coelho et al., 2015). CA functions in promoting the utilization efficiency of inorganic carbon in photosynthesis by regulating intracellular and extracellular inorganic carbon concentrations (Xia et al., 2021). Although the conversion of nitrate to nitrite was slightly inhibited by LL2, the highly induced expression of CA, NirA (Lardi et al., 2016), and GLUL (Seabra and Carvalho, 2019) revealed superior carbon and nitrogen utilization efficiency in G9 plants (Figure 5 and 11), one of the reasons for the high yield of G9.

\section{Plant immunity plays vital roles in determining the specificity of Rhizobium-alfalfa symbiosis}

Plant innate immunity, the non-specific immune system acting promptly against a broad spectrum of microorganisms, is briefly activated immediately after rhizobium infection (Genre et al., 2020). In the meantime, rhizobial cells will actively suppress or evade the plant innate immunity from being targeted as invading pathogens by their compatible hosts (Cyril and Giles, 2017; Upson et al., 2018). This kind of specific perception between host plants and rhizobial strains allowed for the establishment of successful symbiotic systems (Kang et al., 2020). The overall downregulated expression of plant-pathogen related genes in this study resembled the transcriptome profiles of $L$. japonicus, with no early defense response stimulated by the compatible rhizobium strains (Kelly et al., 2018). Specifically, PAMP immunity was promptly triggered by LL2 infection, with G9 plants eliciting a stronger hypersensitive response (HR) and structural barriers to bacterial invasion resulting from the elevated expression of CDPK, Rboh, and CaM/CML. Some immune response-activated genes, namely TIR-NBS-LRR, LRR-RLK, EF-hand pair protein, and WAKL (Kumar et al., 2020) were also induced excessively in G9 plants compared with G3 plants (Figure 4b). Despite the slight induction of defense response-related genes, namely FLS2, MEKK1, and WRKY2533 (Liu et al., 2017), in G9 plants, as well as the marginally suppressed disease resistance proteins, namely RPM1 (NBS-LRR, LRR, and NB-ARC) and RPS2, in G3 plants, both defense-related gene induction (i.e., PR1) and the S. meliloti secretion system, which triggers the ETI process (i.e., HSP90), were induced to a larger extent in G3 plants, indicating an enhanced defense response/resistance of G3 plants to bacteroids (Li et al., 2020). The ubiquitin proteasome system (UPS) induces, regulates, and terminates plant responses to stress, and E3 ubiquitin ligase can positively regulate plant tolerance to biological stress ( $\mathrm{Li}$ et al., 2020). The same expression pattern of E3 ubiquitin ligase genes indicated a more severe inhibition of biotic stress resistance in G3 than G9 plants. 
These results suggest that G9 plants adopt PAMP-triggered immunity to counter LL2 infection, making for a better cost-gain trade-off for the host. This fine-tuned immune antagonism is also an embodiment of high symbiotic specificity. In contrast, the impairment of PTI makes G3 more likely to be interfered by external factors (i.e., abiotic stress, insects, and viruses) other than the inoculated strain LL2. More importantly, the elevated defense response and ETI process led to an earlier degradation of symbionts and bacteriods, nodule senescence, and an inferior symbiotic outcome for G3 plants.

\section{Hub genes govern the specificity of rhizobia-alfalfa symbiosis}

In the interaction networks constructed by the three gene modules most related to biomass synthesis, hub genes encoding NCR, TIR-NBS-LRR, defensin, thioredoxin, thionine, late nodulin, and polygalacturonase were primarily used as source nodes to regulate other genes. In addition to TIR-NBS-LRR and NCR, which are crucial for plant immunity and specificity, thionin and defensin are a class of small molecular weight polypeptide antibiotics and have inhibitory or killing effects on pathogenic microorganisms, such as bacteria and fungi (Zong et al., 2010). Thioredoxin determines plant susceptibility to disease and is necessary for nitrogen-fixing symbiosis (Lai et al., 2014; Alloing et al., 2018), and polygalacturonase is an important disease resistance enzyme (Zhang and Tang, 2021). The detection of these genes substantiated the regulatory role of plant immunity in determining the symbiosis specificity of rhizobiaalfalfa. Further experiments will be needed to verify the specific functions of the abovementioned genes in the symbiosis process in order to elucidate molecular points for the highly efficient symbiotic breeding of legume and/or non-legume plants.

\section{Conclusions}

S. meliloti strain LL2 induced a much better symbiotic performance in alfalfa cultivar G9 than G3. Strain LL2 promoted dry matter accumulation of G9 by maintaining the plant immune response to an antagonism-compatibility balanced degree, as well as enhancing nitrogen fixation and utilization efficiency by inducing the expression of genes encoding NCRs, nodulin, and leghemoglobin. The plant immune system and NCRs are crucial for the specificity of alfalfa cultivar-rhizobia strain symbiosis, in which NCRs, late nodulin, and TIR-NBS-LRR genes play vital roles.

\section{Abbreviations}

NCRs (nodule-specific cysteine-rich peptides); GRPs (nodule-specific glycine-rich proteins); NFs (Nod factors); NBS-LRR (nucleotide-binding domain leucine rich repeat); NR (nitrate reductase NADH -like protein); NirA (ferredoxin-nitrite reductase); CA (carbonic anhydrase); Nrt (high affinity nitrate transporter); GLUL (glutamine synthetase domain protein); ARF-BP1 (alternative reading frame-beta-protein 1); Cull (chitinase); F-box (F-box SKP2A-like protein); SIAH-1 (seven in absentia family protein); Skp1 (S-phase kinase-associated protein 1); UBE2 (ubiquitin-conjugating enzyme E2); UBE3C (E3 ubiquitin-protein ligase); LRR-RLK (LRR receptor-like kinase); CaM/CML (calcium-binding protein); CDPK (calciumdependent protein kinase); CERK1 (LysM domain-containing receptor-like kinase); CNGCs (cyclic 
nucleotide gated channel protein); FLS2 (flagellin sensing 2); HSP90 (heat shock cognate protein 90); MEKK1 (MAP kinase kinase kinase-like protein); PR1 (pathogenesis-related protein 1); Rboh (respiratory burst oxidase-like protein); RPM1 (disease resistance protein RPM1); RPS2 (resistance to Pseudomonas syringae protein 2).

\section{Declarations}

\section{Ethics approval and consent to participate}

Gansu Agricultural University has approved the utilization of seeds and bacteria.

\section{Consent for publication}

Not applicable.

\section{Availability of data and materials}

The RNA-seq datasets presented in this study can be found in GenBank of the NCBI repository, with accession numbers SRR8224072 to SRR8224077 for G3 and SRR8224055, SRR8224058 to SRR8224061, and SRR8224068 for G9 (Additional file 9).

\section{Competing interests}

The authors declare that they have no competing interests

\section{Funding}

This research was funded in part by the National Natural Science Foundation of China (NSFC) (32101427), the Innovation Fund for Higher Education of Gansu Province (2021A-062), the Science and Technology Program of Gansu Province (19ZD2NA002-3), and the National Modern Agricultural Industry Technical system (CARS-34). These funding bodies supported the transcriptome sequencing of plant samples but had no role in the design of the study, collection, analysis, and interpretation of data and in writing the manuscript.

\section{Authors' contributions}

SLS and WJK designed the study. WJK conducted the experiments and analyzed the data. XLL and XYZ performed statistical analyses. WJK wrote the manuscript. SLS contributed to supervision, data analysis, and revision of the manuscript. All authors read and approved the final manuscript.

\section{Acknowledgements}

We appreciate the editor and anonymous reviewers for their constructive comments and the Editage (www.editage.cn) for English language editing. 


\section{References}

1. Alloing G, Mandon K, Boncompagni E, Montrichard F, Frendo P. Involvement of glutaredoxin and thioredoxin systems in the nitrogen-fixing symbiosis between legumes and rhizobia. Antioxidants. 2018;7.doi:10.3390/antiox7120182.

2. Andrews M, Andrews ME. Specificity in legume-rhizobia symbioses. Int J Mol Sci. 2017;18(4): 705.

3. Attla KPM, Jesűs M, Gabriella E, Éva K. Impact of plant peptides on symbiotic nodule development and functioning. Front Plant Sci. 2018; 9: 1026.

4. Benoît A, Benjamin G. Terminal bacteroid differentiation in the legume-rhizobium symbiosis: nodulespecific cysteine-rich peptides and beyond. New Phytol. 2016; 211: 411-7.

5. Beringer JE. R factor transfer in Rhizobium leguminosarum. J Gen Microbiol. 1974; 84(1): 188 -98.

6. Breakspear A, Liu C, Roy S, Stacey N, Rogers C, Trick M, et al. The root hair "infectome" of Medicago truncatula uncovers changes in cell cycle genes and reveals a requirement for auxin signaling in rhizobial infection. Plant Cell. 2014; 26(12): 4680-701.

7. Burghardt LT, Guhlin J, Chun CL, Liu J, Sadowsky MJ, Stupar RM, et al. Transcriptomic basis of genome by genome variation in a legume-rhizobia mutualism. Mol Ecol. 2017.

8. Charrier A, Bérard JB, Bougaran G, Carrier G, Lukomska E, Schreiber N, et al. High-affinity nitrate/nitrite transporter genes (Nrt2) in Tisochrysis lutea: identification and expression analyses reveal some interesting specificities of Haptophyta microalgae. Physiol Plant. 2015; 154(4):572-90.

9. Coelho C. Structural and mechanistic insights on nitrate reductases. Protein Sci. 2015; 24: 1901-11.

10. Cyril, Z., and Giles, E. D. O. (2017). Plant signalling in symbiosis and immunity. Nature 543(7645): 328-336.

11. Drogue B, Sanguin H, Chamam A, Mozar M, Llauro C, Panaud O, et al. Plant root transcriptome profiling reveals a strain-dependent response during Azospirillum-rice cooperation. Front Plant Sci. 2014; 5:607.

12. Gage DJ. Infection and invasion of roots by symbiotic, nitrogen-fixing rhizobia during nodulation of temperate legumes. Microbiol Mol Biol Rev. 2004;68(2): 280-300.

13. Genre A, Lanfranco L, Perotto S, Bonfante P. Unique and common traits in mycorrhizal symbioses. Nature Reviews Microbiology. 2020;18(11):1-12

14. Gergel YM, Éva K. Nitrogen-fixing Rhizobium-legume symbiosis: are polyploidy and host peptidegoverned symbiont differentiation general principles of endosymbiosis? Front Microbio. 2014; 5: 326.

15. Gourion B, Berrabah F, Ratet P, Stacey G. Rhizobium-legume symbioses: the crucial role of plant immunity. Trends Plant Sci. 2015; 20(3): 186-94.

16. Grabherr MG, Haas BJ, Yassour M, Levin JZ, Thompson DA, Amit I, et al. Trinity: reconstructing a fulllength transcriptome without a genome from RNA-Seq data. Nat Biotechnol. 2011; 29(7):644-52. 
17. Huyghe A, Bakkou N, Perret X. Profiling symbiotic responses of Sinorhizobium fredii strain NGR234 with RNA-Seq. In: Biological Nitrogen Fixation. 2015; pp.649-658. doi:10.1002/9781119053095.ch65

18. Jardinaud MF, Boivin S, Rodde N, Catrice O, Kisiala A, Lepage A, et al. A laser dissection-RNAseq analysis highlights the activation of cytokinin pathways by nod factors in the Medicago truncatula root epidermis. Plant Physiol. 2016; 171(3):2256-76.

19. Upson JL, Zess EK, Białas A, Wu CH, Kamoun S. The coming of age of EvoMPMl: evolutionary molecular plant-microbe interactions across multiple timescales. Curr Opin in Plant Biol. 2018; 44:108-116.

20. Kang WJ, Shi SL, Xu L. Diversity and symbiotic divergence of endophytic and non-endophytic rhizobia of Medicago sativa. Ann Microbiol. 2018; 68(5):247-60.

21. Kelly S, Mun T, Stougaard J, Ben C, Andersen SU. Distinct Lotus japonicus transcriptomic responses to a spectrum of bacteria ranging from symbiotic to pathogenic. Front Plant Sci. 2018; 9:1218.

22. Kristina L, Seyed AM. Effectiveness of nitrogen fixation in rhizobia. Microb Biotechnol. 2019; 1-22.

23. Kumar MK, Ashish R, Jyothi HS, Kumar PH, Sonti RV. Dual activities of receptor-like kinase oswakl21.2 induce immune responses1. Plant Physiol. 2020; (3):3.

24. Lai Z, Schluttenhofer CM, Bhide K, Shreve J, Thimmapuram J, Lee SY, et al. MED18 interaction with distinct transcription factors regulates multiple plant functions. Nature Commun. 2014; 5: 3064. doi: 10.1038/ ncomms 4064.

25. Langfelder P, Steve H. WGCNA: an R package for weighted correlation network analysis. BMC Bioinformatics. 2008; 9(1): 559.

26. Larrainzar E, Riely BK, Kim SC, Carrasquilla-Garcia N, Yu HJ, Hwang HJ, et al. Deep sequencing of the Medicago truncatula root transcriptome reveals a massive and early interaction between nod factor and ethylene signals. Plant Physiol. 2015;169(1):233-65

27. Li B, Dewey CN. RSEM: accurate transcript quantification from RNA-Seq data with or without a reference genome. BMC Bioinformatics. 2011;12(1):323.

28. Li JF, Zhang SQ, Shi SL, Huo PH. Position and quantity of endogensis rhizobia in alfalfa plant. Chinese J Eco-Agr.2009;17(6):1200-1205.

29. Li Q, Serio RJ, Schofield A, Liu H, Rasmussen SR, Hofius D, et al. Arabidopsis ring-type e3 ubiquitin ligase xbat35.2 promotes proteasome-dependent degradation of acd 11 to attenuate abiotic stress tolerance. Plant J. 2020.

30. Li YH, Qiu LN, Liu XY, Krugman T, Zhang Q, Zhuansun XX, et al. Glycerol-induced powdery mildew resistance in wheat by regulating plant fatty acid metabolism, plant hormones cross-talk, and pathogenesis related genes. Int J Mol Sci. 2020;21: 673.

31. Liu J, Yang S, Zheng Q, Zhu H. Identification of a dominant gene in Medicago truncatula that restricts nodulation by Sinorhizobium meliloti strain Rm41. BMC Plant Biol. 2014;14(1): 167.

32. Liu Q, Liu Y, Tang Y, Chen J, Ding W. Overexpression of NtWRKY50 increases resistance to Ralstonia solanacearum and alters salicylic acid and jasmonic acid production in Tobacco. Front Plant Sci. 
2017; 8:1710. doi: 10.3389/fpls.2017.01710

33. Lindström L, Mousavi SA. Effectiveness of nitrogen fixation in rhizobia. Microbial Biotechnol. 2019;122.

34. Livak K, Schmittgen T. Analysis of Relative Gene Expression Data Using Real-Time Quantitative PCR and the $2^{-\triangle \triangle C t}$ Method. Methods. 2001;25(4): 402-408.

35. Lardi M, Murset V, Fischer HM, Mesa S, Ahrens CH, Zamboni N, et al. Metabolomic profiling of Bradyrhizobium diazoefficiens-induced root nodules reveals both host plant-specific and developmental signatures. Int J Mol Sci. 2016; 17(6), 815.

36. Matthew B, Crook CC, Lindsay MJCDP, Biggs MB, Long SR, Bentley JS, et al. Rhizobial Plasmids That Cause Impaired Symbiotic Nitrogen Fixation and Enhanced Host Invasion. Mol Plant Microbe In. 2012;25(8): 1026-33.

37. Miao YY, Shi SL, Zhang JG, Mohamad OA. Migration, colonization and seedling growth of rhizobia with matrine treatment in alfalfa (Medicago sativa L.). Acta Agr Scand B-S P. 2018; 68 (1):26-38. doi: 10.1080/09064710.2017.1353131

38. Minour K, Michihiro A, Susumu G, Masahiro H, Mika H, Masumi I, et al. KEGG for linking genomes to life and the environment. Nucleic Acids Res. 2007; 36(suppl_1): 480-484.

39. Nobori T, Velásquez AC, Wu J, Kvitko BH, Kremer JM, Wang Y, et al. Transcriptome landscape of a bacterial pathogen under plant immunity. Proc Natl Acad Sci U S A. 2018;115(13): E3055-64.

40. Paungfoo-Lonhienne C, Lonhienne TGA, Yeoh YK, Donose BC, Webb RI, Parsons J, et al. Crosstalk between sugarcane and a plant-growth promoting Burkholderia species. Sci Rep. 2016;6: 37389.

41. Pérez-Montaño F, Jiménez-Guerrero I, Acosta-Jurado S, Navarro-Gómez P, Ollero F J, Ruiz-Sainz JE, et al. A transcriptomic analysis of the effect of genistein on Sinorhizobium fredii $\mathrm{HH} 103$ reveals novel rhizobial genes putatively involved in symbiosis. Sci Rep. 2016;6(1): 31592.

42. Perret X, Staehelin C, Broughton W J. Molecular basis of symbiotic promiscuity. Microbiol Mol Biol Rev. 2000;64(1): 180-201.

43. Powell AF, Doyle JJ. Non-additive transcriptomic responses to inoculation with rhizobia in a young allopolyploid compared with its diploid progenitors. Genes. 2017;8(12):357.

44. Roy P, Achom M, Wilkinson H, Lagunas B, Gifford ML. Symbiotic Outcome Modified by the Diversification From 7 to Over 700 Nodule-Specific Cysteine-Rich Peptides. Genes. 2020;11(4), 348.

45. Reinhold-Hurek B, Hurek T. Living inside plants: bacterial endophytes. Curr Opin Plant Biol. 2011;14(4):435-43.

46. Robinson MD, McCarthy DJ, Smyth GK. edgeR: a bioconductor package for differential expression analysis of digital gene expression data. Bioinformatics. 2010;26(1):139-40.

47. Sánchez, F., Servín, L., Márquez, Y., Timoteo, O. P., Zamudio, F. Z., Rodríguez-Kessler M., et al. (2011). Nodulin 41, a novel late nodulin of common bean with peptidase activity. BMC Plant Biology 11(1), 134. 
48. Schumpp O, Deakin WJ. How inefficient rhizobia prolong their existence within nodules. Trends Plant Sci. 2010;15(4): 0-195.

49. Seabra AR, Carvalho H. Inhibition of glutamine synthetase leads to a fast transcriptional activation of defense responses in root nodules. The Model Legume Medicago truncatula. In: The Model Legume Medicago truncatula. 2019; pp.665-673). doi:10.1002/9781119409144.ch82.

50. Shannon P, Markiel A, Ozier O, Baliga NS, Wang JT, Ramage D, et al. Cytoscape: a software environment for integrated models of biomolecular interaction networks.Genome Res. 2003;13(11):2498-504.

51. Soto MJ, DomÍnguez-Ferreras A, Pérez-Mendoza D, Juan SJ, Jose O. Mutualism versus pathogenesis: the give-and-take in plant-bacteria interactions. Cell Microbiol. 2009;11(3): 381-388.

52. Spaink HP. Root nodulation and infection factors produced by rhizobial bacteria. Annual Reviews in Microbiol. 2000;54(1): 257-288.

53. Nallu S, Silverstein KAT, Zhou P, Young ND, Vandenbosch KA. Patterns of divergence of a large family of nodule cysteine-rich peptides in accessions of Medicago truncatula. Plant J. 2014;78(4): 697-705.

54. Sinclair TR, Rufty TW, Lewis RS. Increasing photosynthesis: unlikely solution for world food problem. Trends Plant Sci. 2019.

55. Van ZA, Camp RHMOD, Deinum EE, Charnikhova T, Franssen H, Camp HJMOD, et al. Rhizobium Lipochitooligosaccharide signaling triggers accumulation of cytokinins in Medicago truncatula roots. Mol Plant. 2015;8(8):1213-26.

56. Walker L, Lagunas B, Gifford ML. Determinants of Host Range Specificity in Legume-Rhizobia Symbiosis. Front Microbiol. 2020;11.

57. Wang D, Yang S, Tang F, Zhu H. Symbiosis specificity in the legume -rhizobial mutualism. Cell Microbiol. 2012;14(3):334-42.

58. Wang Q, Yang S, Liu J, Terecskei K, Ábrahám E, Gombár A, et al. Host-secreted antimicrobial peptide enforces symbiotic selectivity in Medicago truncatula. Proc Natl Acad Sci U S A. 2017;114(26): 6854-6859.

59. Kang W, Jiang Z, Chen Y, Wu F, Zhang XX. Plant transcriptome analysis reveals specific molecular interactions between alfalfa and its rhizobial symbionts below the species level. BMC Plant Biology. 2020,20: 293.

60. Willem VDV, Grigor Z, Agnes S, Monika D, Hironobu I, Zoltan K, et al. Plant Peptides Govern Terminal Differentiation of Bacteria in Symbiosis. Science. 2010; 327(5969): 1122-1126.

61. Wu TD, Nacu S. Fast and SNP-tolerant detection of complex variants and splicing in short reads. Bioinformatics. 2010;26(7): 873-881.

62. Xia JR, Chen X, Giordano M, Anhydrase C. Research Methods of Environmental Physiology in Aquatic Sciences. 2021.

63. Yuan S, Li R, Chen S, Chen H, Zhang C, Chen L, et al. RNA-Seq analysis of differential gene expression responding to different rhizobium strains in soybean (Glycine max) roots. Front Plant Sci. 
$2016 ; 7: 721$.

64. Zhang XX, Turner SL, Guo XW, Yang HJ, Debelle F, Yang GP, et al. (). The common nodulation genes of Astragalus sinicus rhizobia are conserved despite chromosomal diversity. Appl Environ Microbiol. 2000;66(7): 2988-2995.

65. Zhang Y, Tang M. Effects of arbuscular mycorrhizal fungi on biomass and disease-resistance enzyme activity of Cathay poplar against canker. Mycosystema. 2021;40(2): 1-12.

66. Zhang Y, Xia R, Kuang H, Meyers BC. (). The diversification of plant NBS-LRR defense genes directs the evolution of microRNAs that target them. Mol Biol Evol.2016;33(10):2692-705.

67. Zong XJ, Wang JW, Liu QZ. Researches on Thionins and Defensins in Plant Disease Resistance Breeding. Biotechnology Bulletin. $2010 ;(03): 21-24$.

\section{Figures}


a
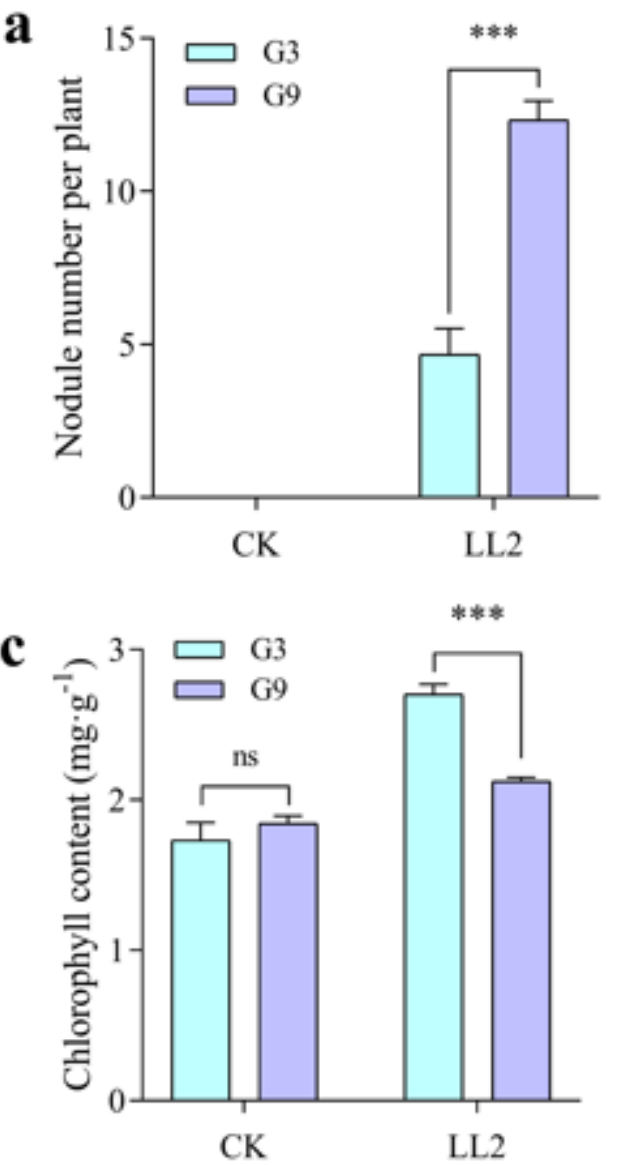

e

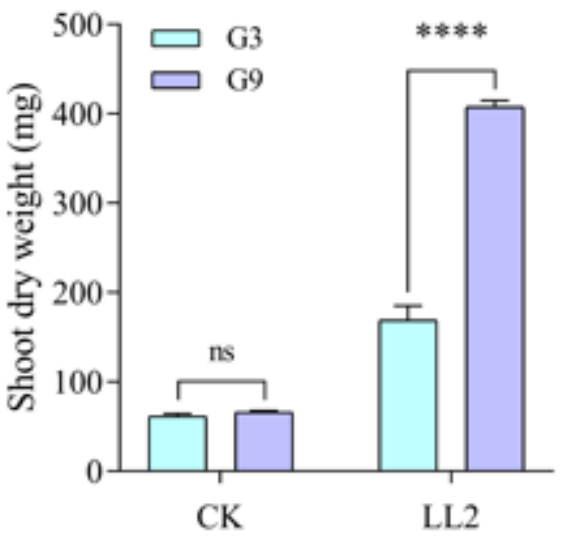

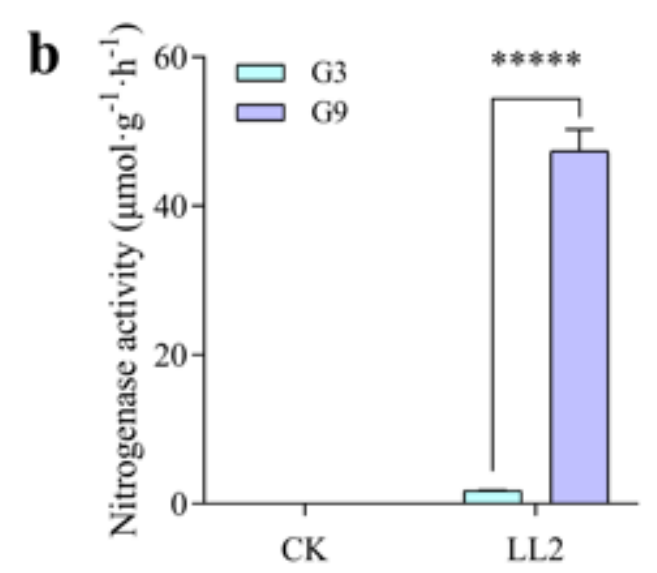

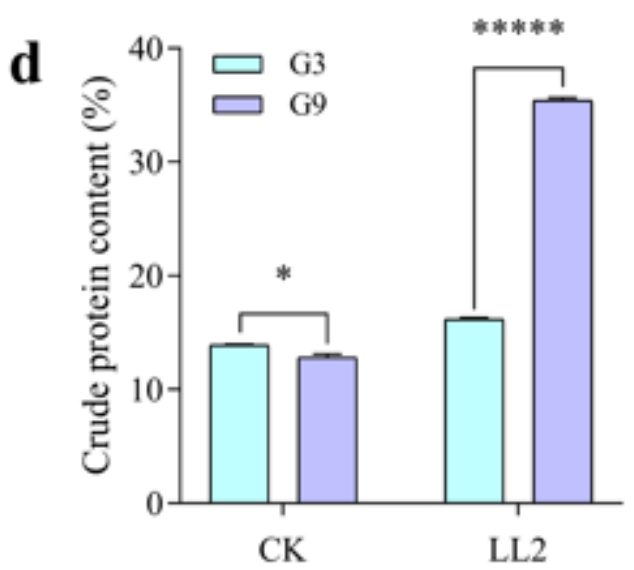

f

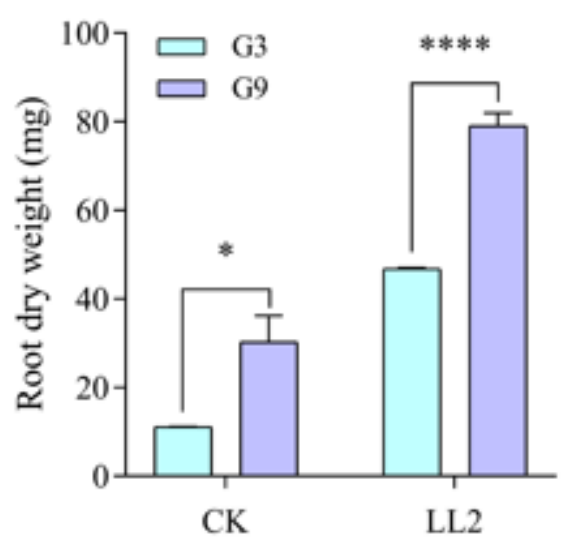

Figure 1

Symbiotic efficiency of Sinorhizobium meliloti strain LL2 on alfalfa cultivars Medicago sativa cv.

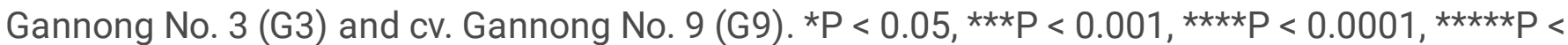
0.00001 , ns: $P>0.05$. Data are shown as the mean \pm standard error (SE) of 10 seedlings in each of the four biological duplicates. 


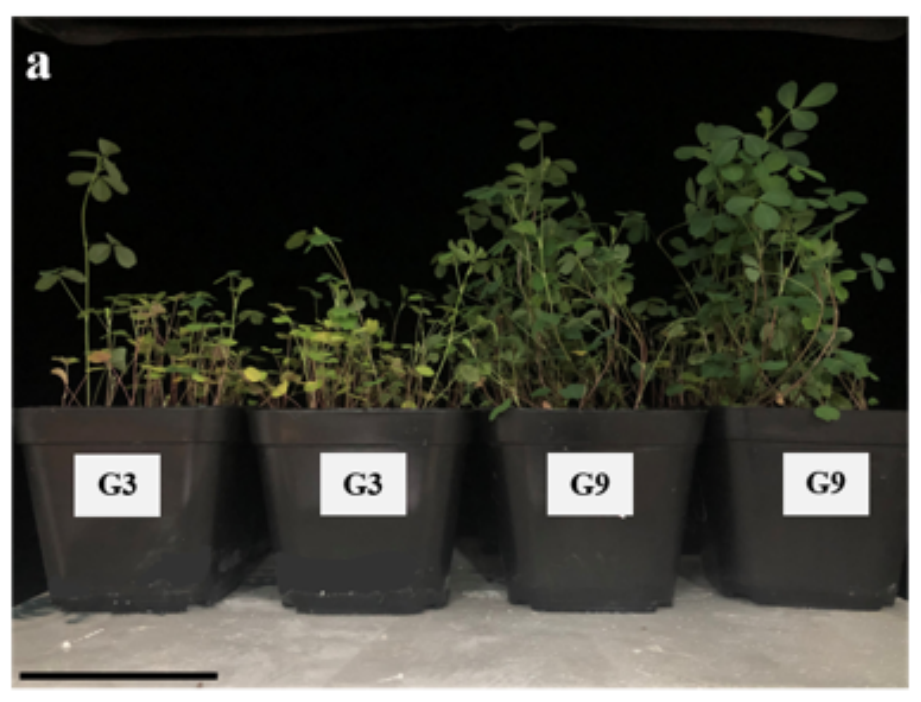

\section{5dpi}
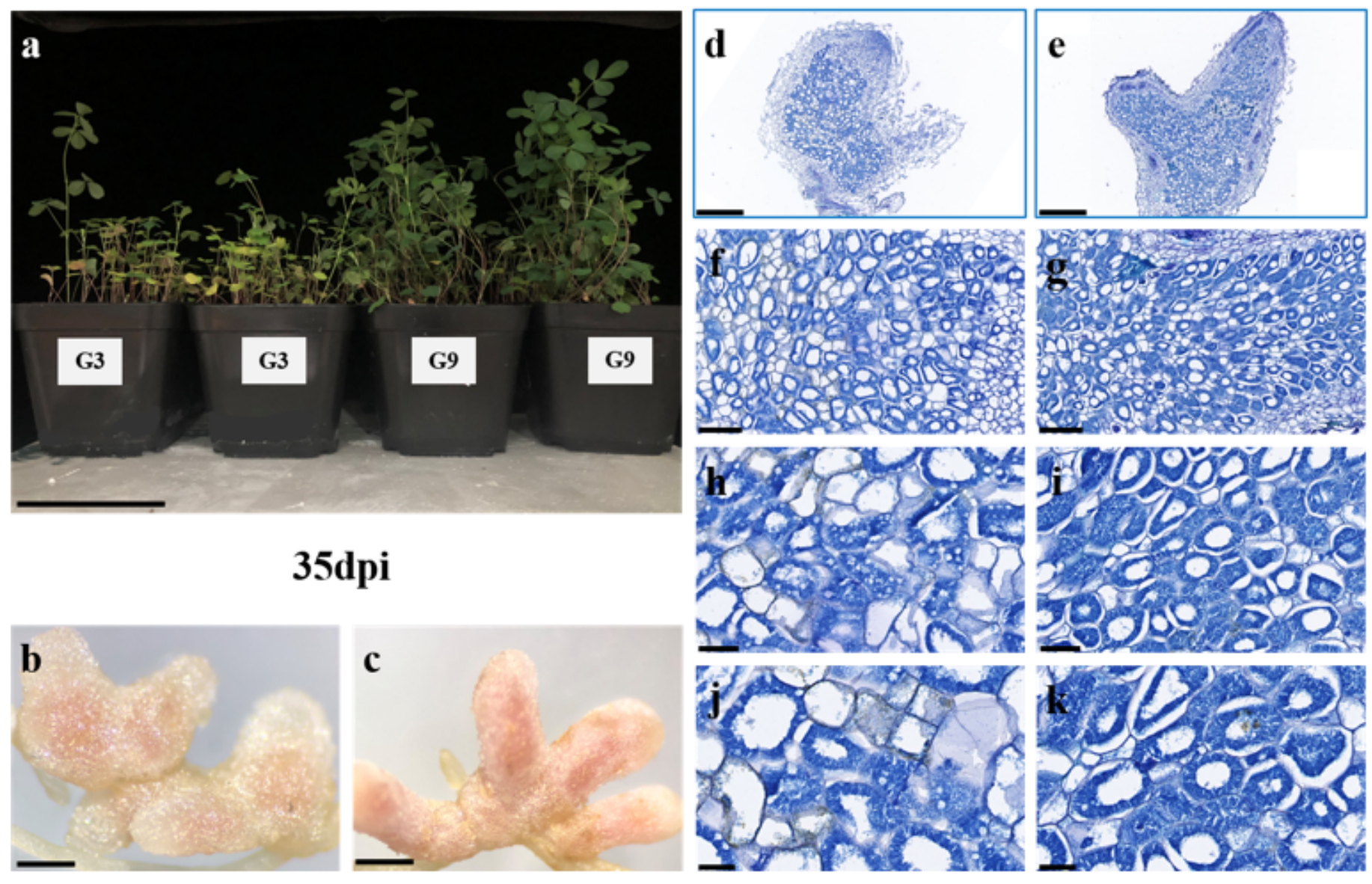

Figure 2

Phenotype and microscopy of nodules obtained from alfalfa cultivars Medicago sativa cv. Gannong No. 3 (G3) (a, b, d, f, h, j) and cv. Gannong No. 9 (G9) (a, c, e, g, i, k) at 35 dpi. Semithin (4 $\mu \mathrm{m})$ sections were stained with toluidine blue. Scale bar: (a) $10 \mathrm{~cm}$; (b, c) 2 mm; (d, e) $200 \mu \mathrm{m} ;(f, g) 50 \mu \mathrm{m}$; (h, i) $20 \mu \mathrm{m} ;(\mathrm{j}, \mathrm{k})$ $10 \mu \mathrm{m}$. 
a Alfalfa cultivars
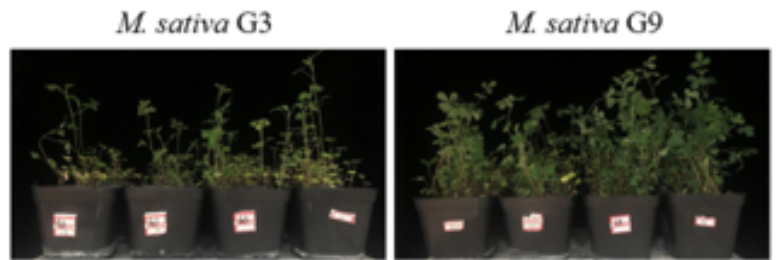

Inoculation time: $15^{\text {th }}$

CK S. meliloti LL2

CK S. meliloti LL2,

Sample time

45 dpi

RNA-seq tissue

Hair roots

Nodulated

hair roots

Hair roots

Nodulated hair roots

Replicates

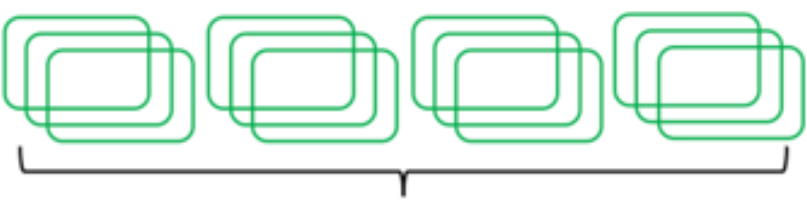

12 biological replicates

\section{b}

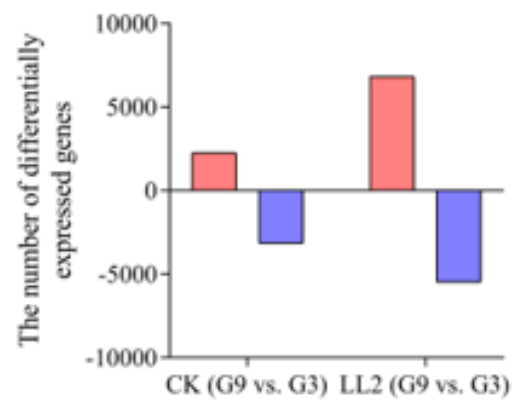

d

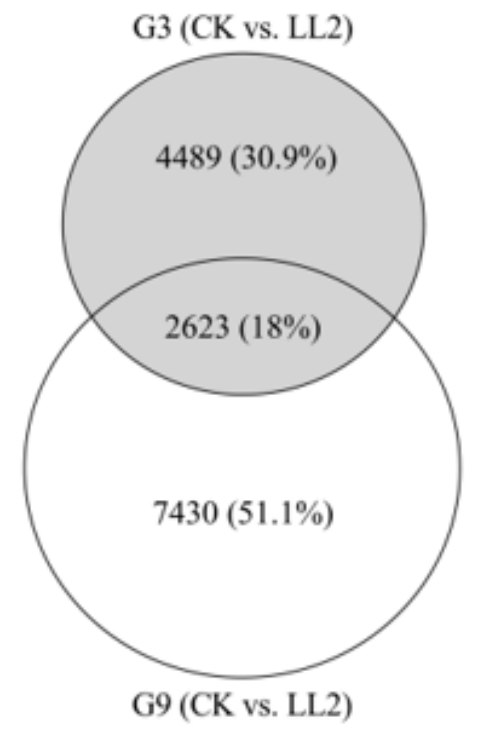

c

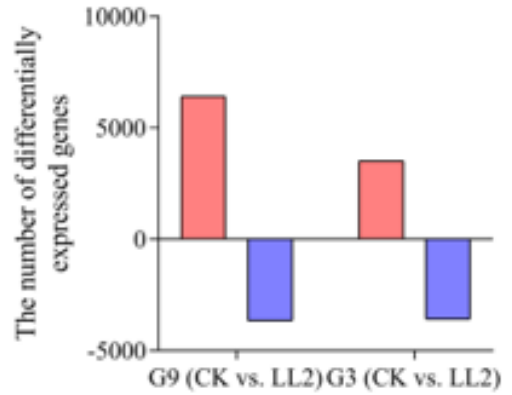

e

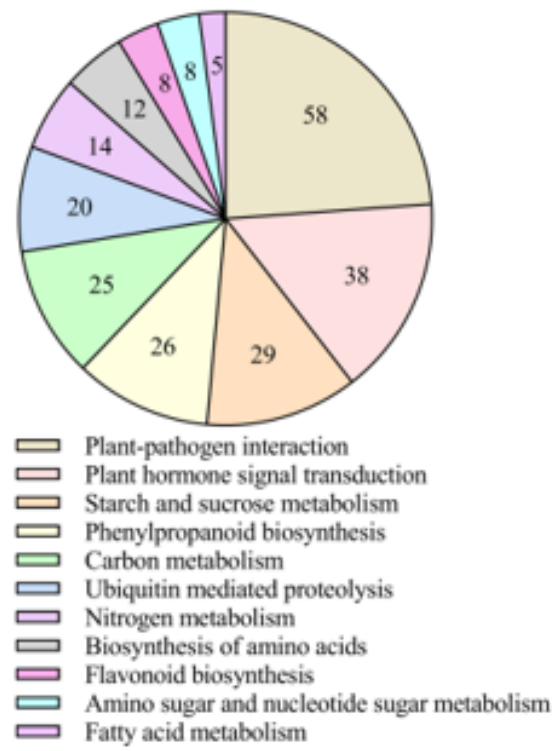

\section{Figure 3}

Expression patterns of genes differentially expressed after LL2 inoculation in the alfalfa cultivars G3 and G9. (a) Experimental design. (b) The number of differentially expressed genes between G9 and G3 prior (CK) and post LL2 inoculation. (c, d) The number of differentially expressed genes in G9 and G3 induced by LL2 inoculation. (e) KEGG pathways linked to symbiotic symbiosis. 
a

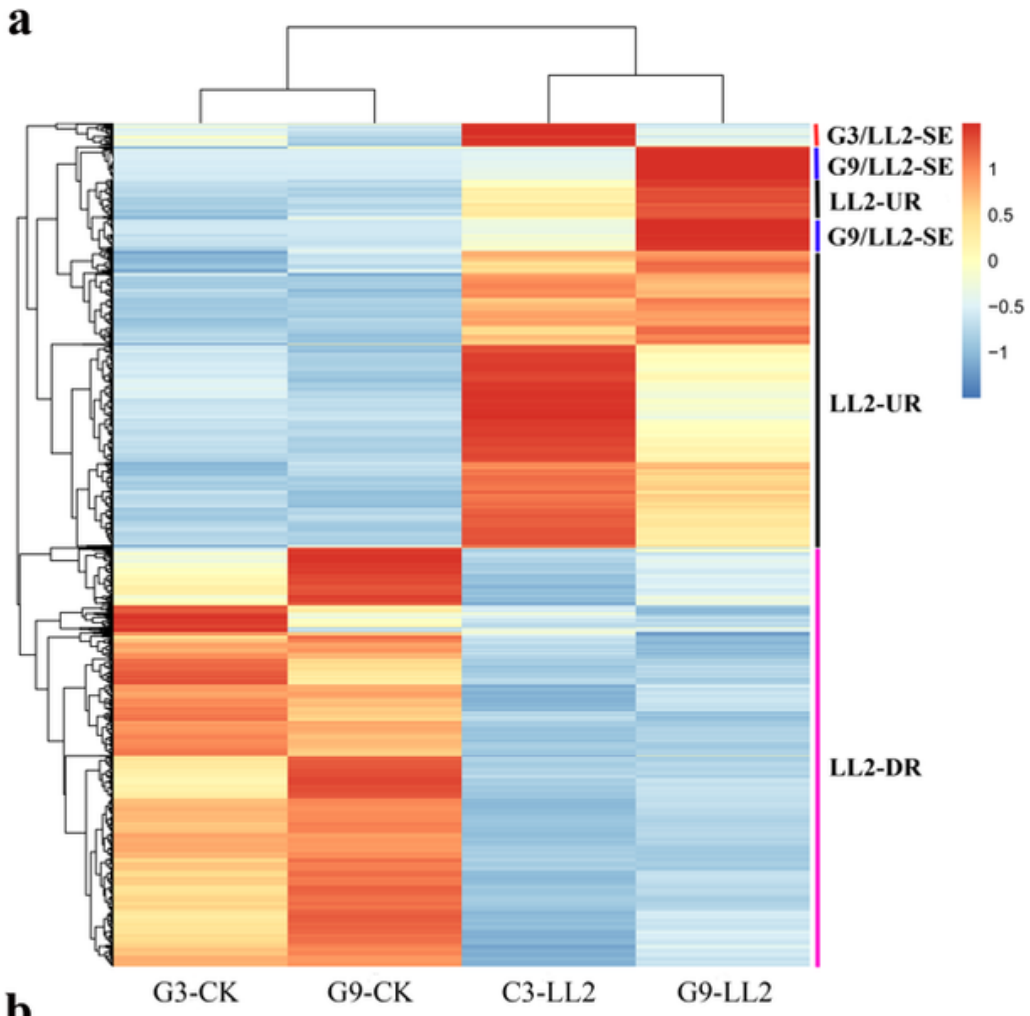

b
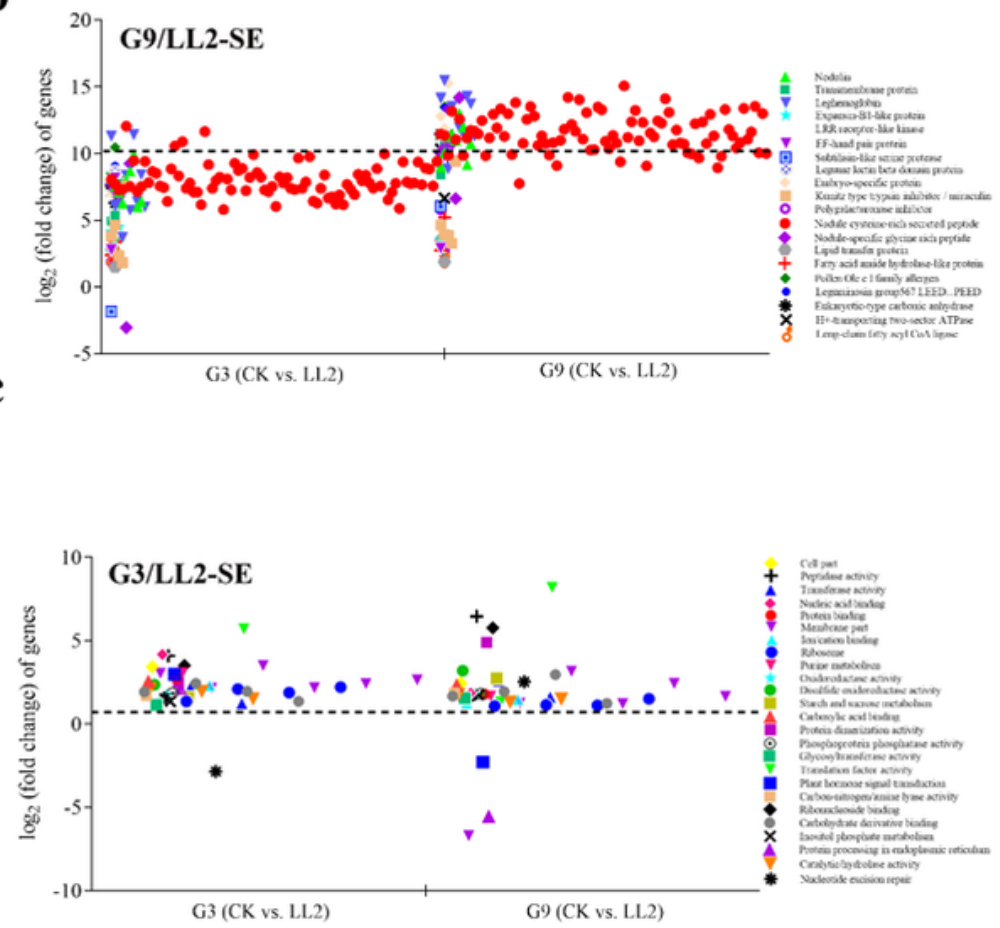

\section{Figure 4}

Heat map and function annotation of differentially expressed genes (DEGs). (a) The heat map of DEGs constructed based on the FPKM values by using the R package Pheatmap. LL2-DR: genes specifically downregulated upon LL2 inoculation; G9/LL2-SE and G3/LL2-SE: genes specifically expressed in G9-LL2 and G3-LL2 treatments; LL2-UR, genes specifically upregulated upon LL2 inoculation. (b) Functional annotation of G9/LL2-SE genes. (C) Functional annotation of G3/LL2-SE genes. 


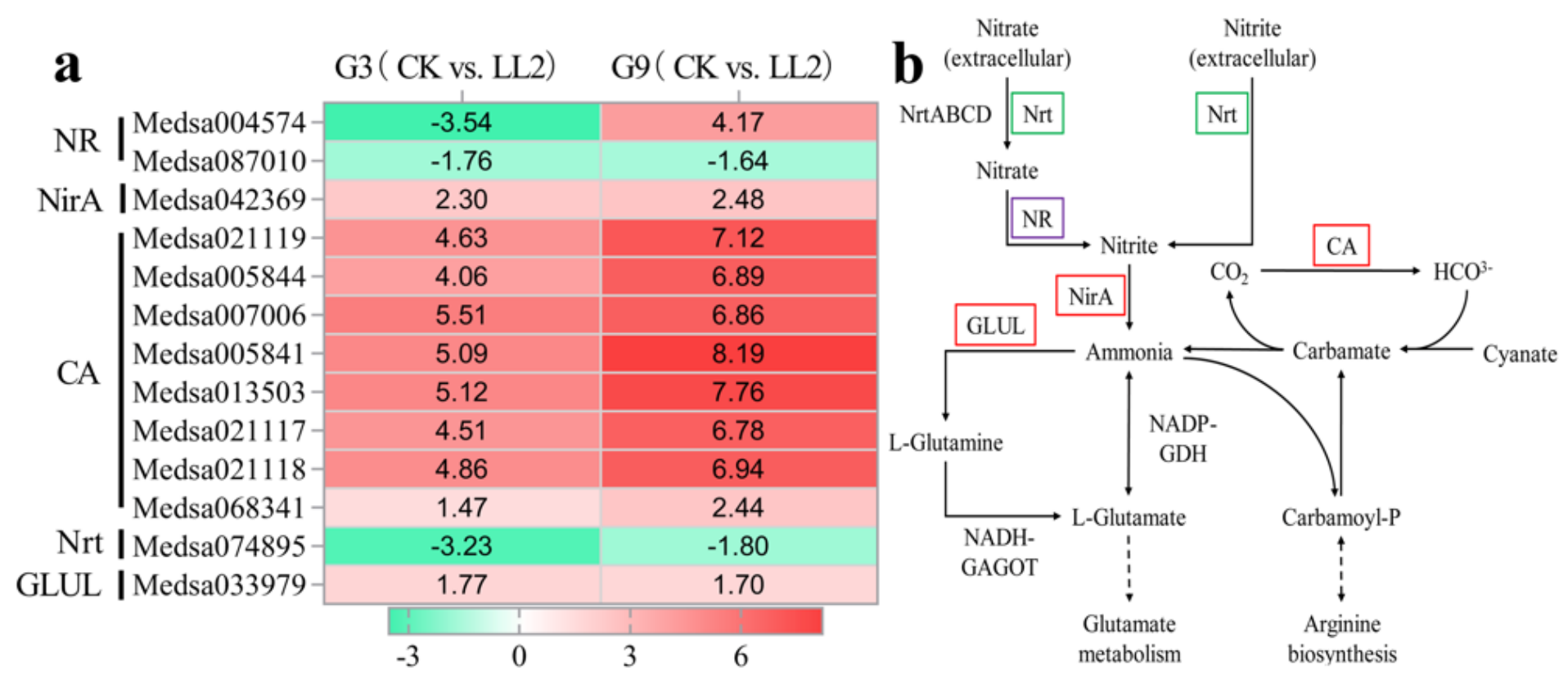

\section{Figure 5}

Differentially expressed genes involved in nitrogen metabolism in cultivars G3 and G9 (a) and simplified nitrogen metabolic process induced by S. meliloti infection (b). Data are shown as the log2 (fold change) values for each differentially expressed gene. NR: nitrate reductase NADH -like protein; NirA: ferredoxinnitrite reductase; CA: carbonic anhydrase; Nrt: high-affinity nitrate transporter; GLUL: glutamine synthetase domain protein. Red, green, and purple boxes represent the upregulation, downregulation, and inconsistent expression of genes, respectively. 


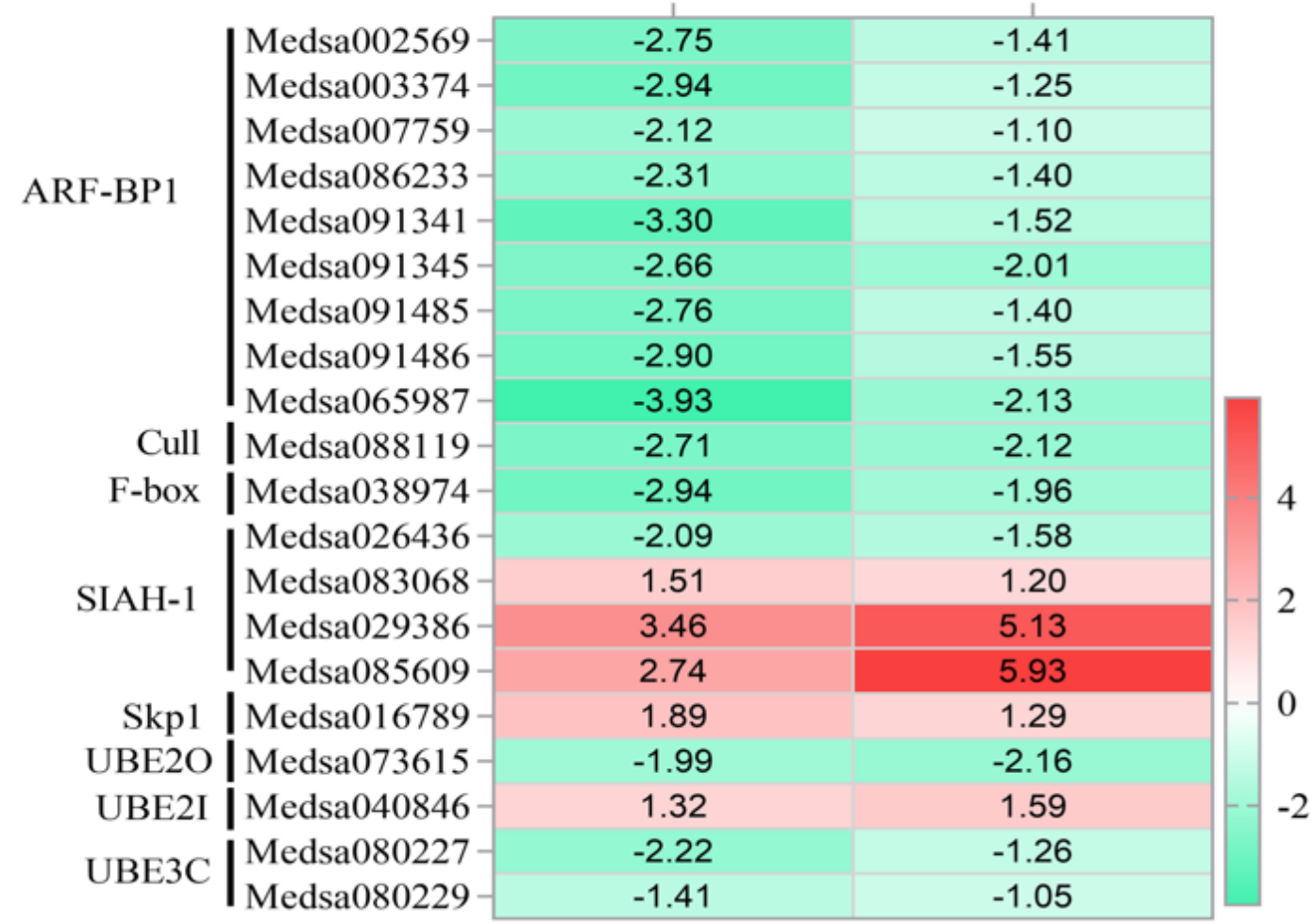

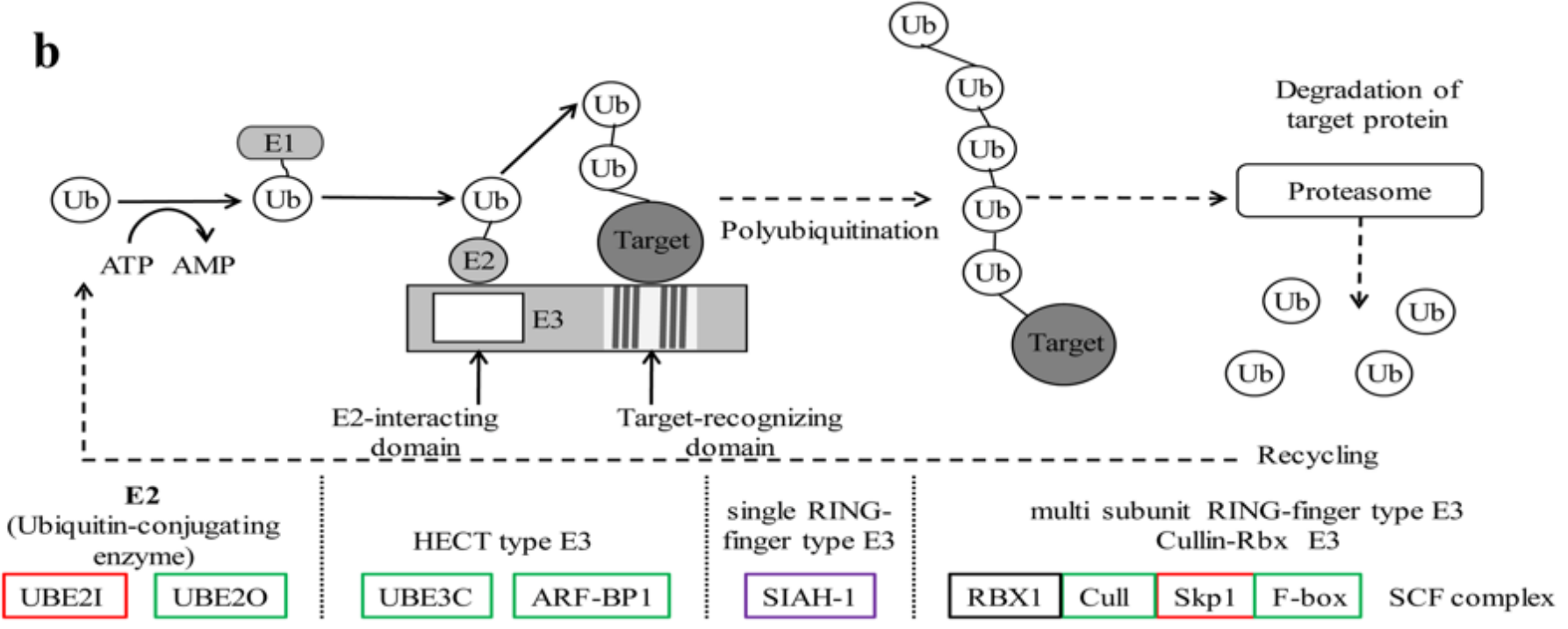

\section{Figure 6}

Differentially expressed genes involved in ubiquitin mediated proteolysis in cultivars G3 and G9 (a) and key ubiquitin-conjugating enzyme E2 and E3 ubiquitin-protein ligase induced by S. meliloti infection (b). Data are shown as the log2 (fold change) values for each differentially expressed gene. ARF-BP1: alternative reading frame-beta-protein 1; Cull: chitinase; F-box: F-box SKP2A-like protein; SIAH-1: seven in absentia family protein; Skp1: S-phase kinase-associated protein 1; UBE2: ubiquitin-conjugating enzyme E2; UBE3C: E3 ubiquitin-protein ligase. Red, green, and purple boxes represented the upregulation, downregulation, and inconsistent expression of genes, respectively. 


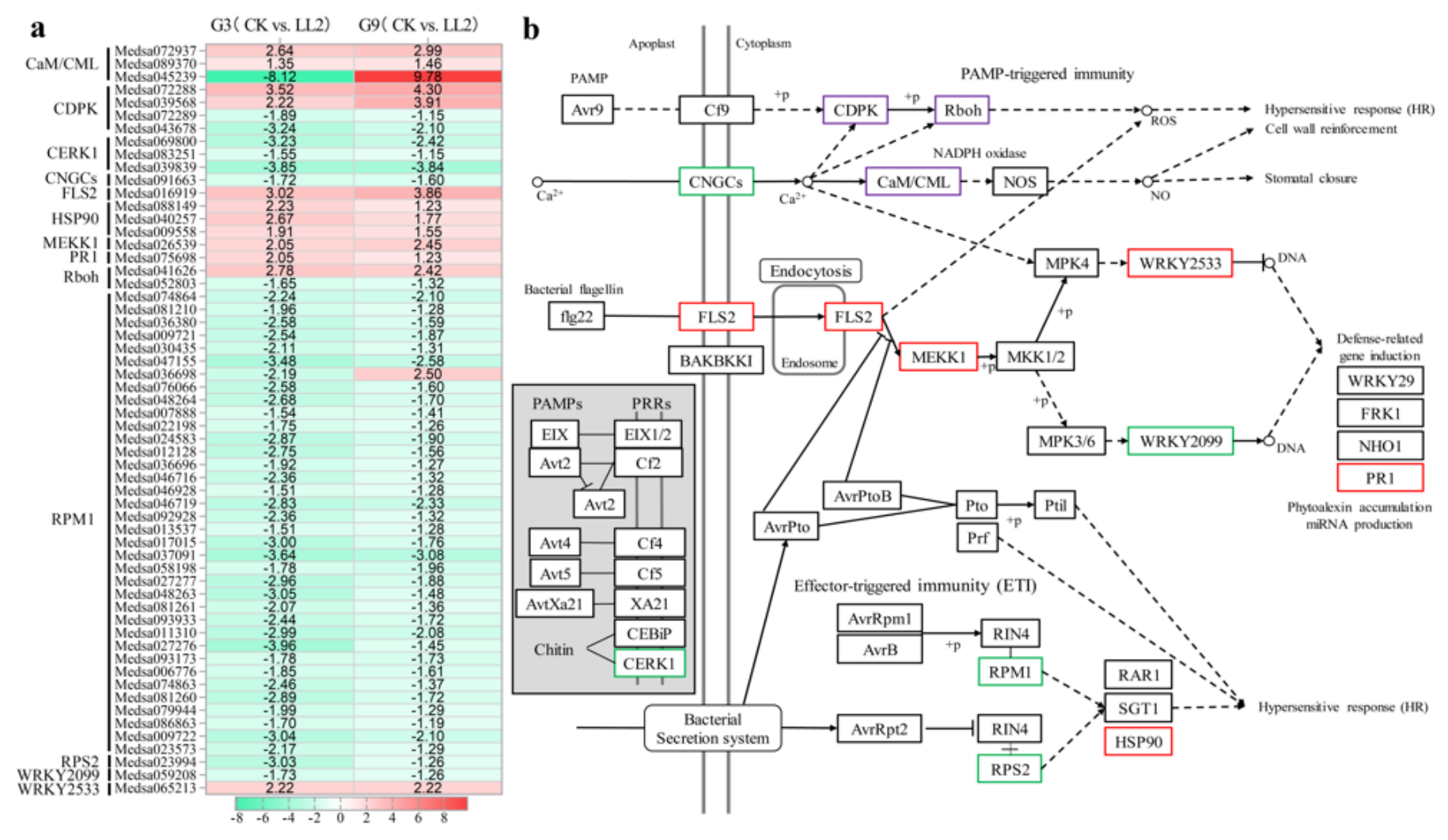

Figure 7

Differentially expressed genes involved in plant-pathogen interaction in cultivars G3 and G9 (a) and simplified plant immunity response induced by S. meliloti infection (b). Data are shown as the log2 (fold change) values for each differentially expressed gene. CaM/CML: calcium-binding protein; CDPK: calcium-dependent protein kinase; CERK1: LysM domain-containing receptor-like kinase; CNGCs: cyclic nucleotide gated channel protein; FLS2: flagellin sensing 2; HSP90: heat shock cognate protein 90; MEKK1: MAP kinase kinase kinase-like protein; PR1: pathogenesis-related protein 1; Rboh: respiratory burst oxidase-like protein; RPM1: disease resistance protein RPM1; RPS2: resistance to Pseudomonas syringae protein 2. Red, green, and purple boxes represent the upregulation, downregulation, or inconsistent expression of genes, respectively. 


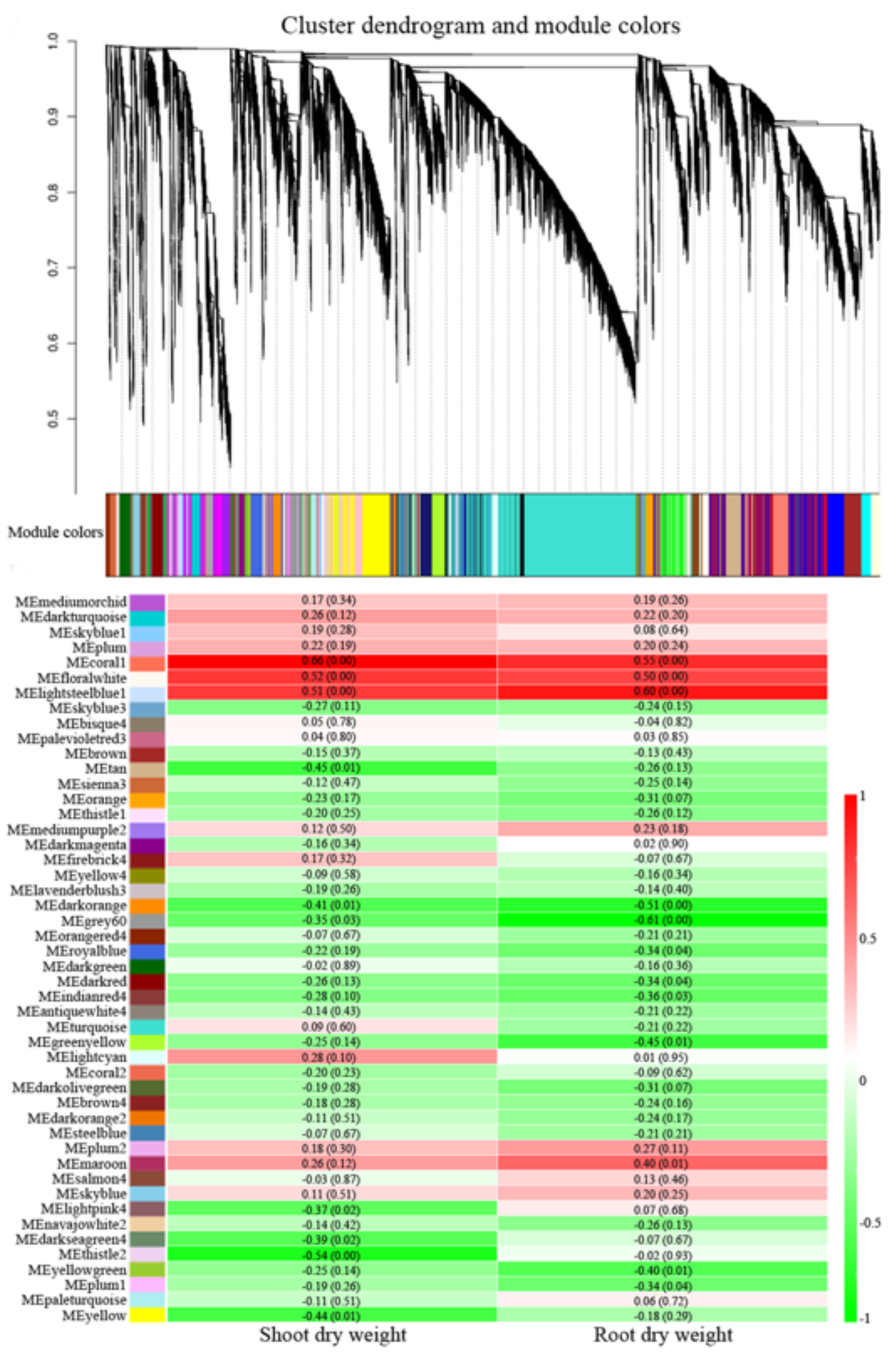

\section{Figure 8}

Weighted gene co-expression network analysis (WGCNA). Co-expression modules identified by WGCNA showing in the hierarchical cluster tree contained different genes (leaves). Forty-eight modules constituting the major tree branches correspond to 48 rows and were labeled by different colors. The correlation coefficient ( $p$-value in brackets) between the module and the trait was presented by the cell color at the row-column interaction, with the color depth indicating the degree of correlation. 


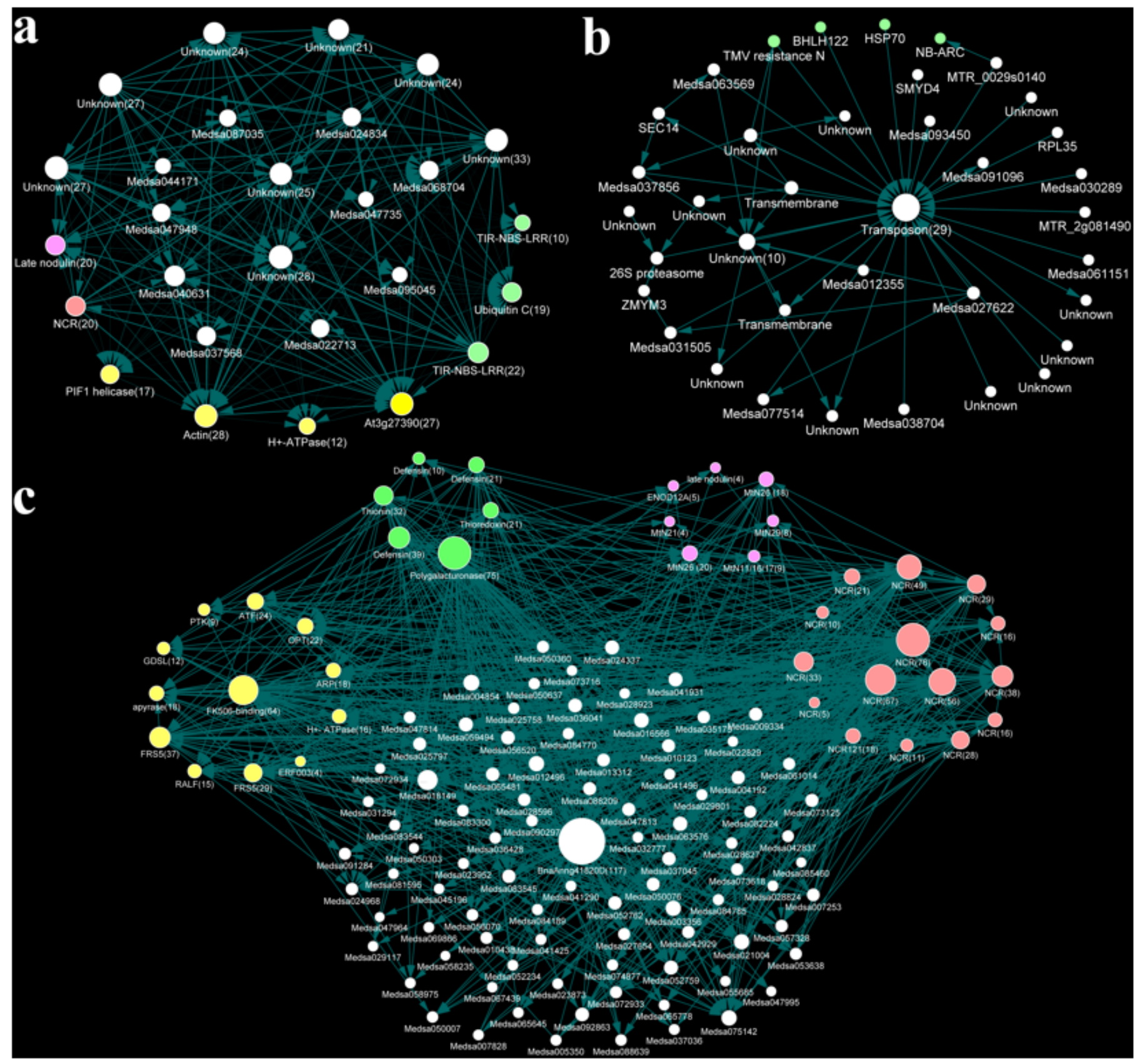

Figure 9

Hub gene interaction networks. (a) Hub gene interaction networks of MEfloralwhite. (b) Hub gene interaction networks of MElightsteelblue 1. (c) Hub gene interaction networks of MEcoral 1. Dots with different sizes represent hub genes (nodes) with different connectivities. The direction of the arrows indicate that the source gene (node) acts on another target gene (node). Numbers in parentheses indicate the number of genes to which the gene is connected. 

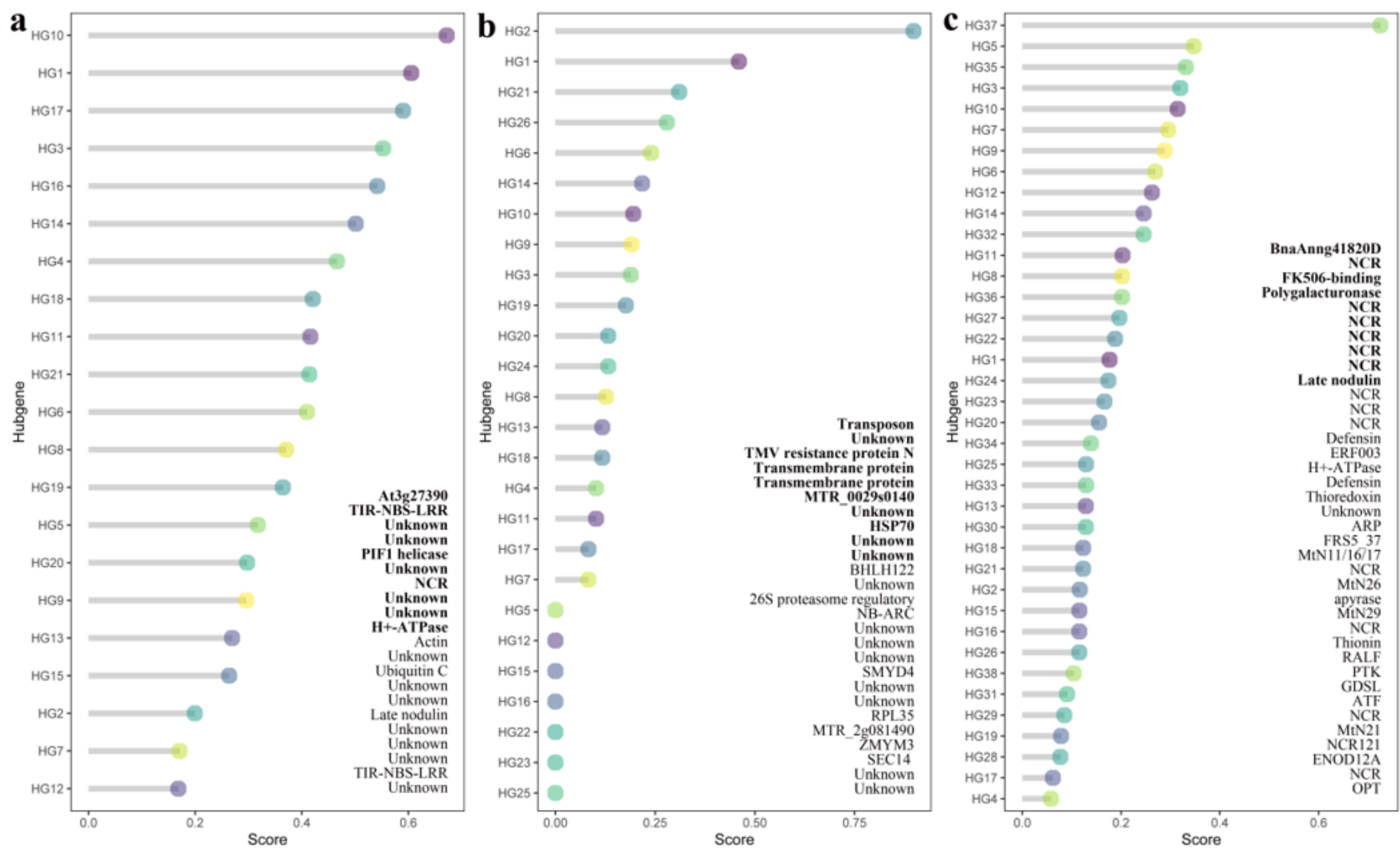

\section{Figure 10}

Hub genes detected from gene modules mostly related to shoot and root dry weight. (a) Hub genes in module MElightsteelblue 1. (b) Hub genes in module MEfloralwhite. (c) Hub genes in module MEcoral 1. Hub genes were detected by using 12 kinds of methods (Betweenness, BottleNeck, Closeness, ClusteringCoefficient, Degree, DMNC, EcCentricity, EPC, MCC, MNC, Radiality, and Stress) in CytoHubba of Cytoscape 3.6.1. Gene names are listed in the lower right corner of each plot. After evaluation using TOPSIS in R 3.6.2, the genes were sorted according to their importance. The top ten hub genes in each module are shown in bold. 
Growth promotion mechanism of

LL2 on alfalfa cultivars G9 and G3

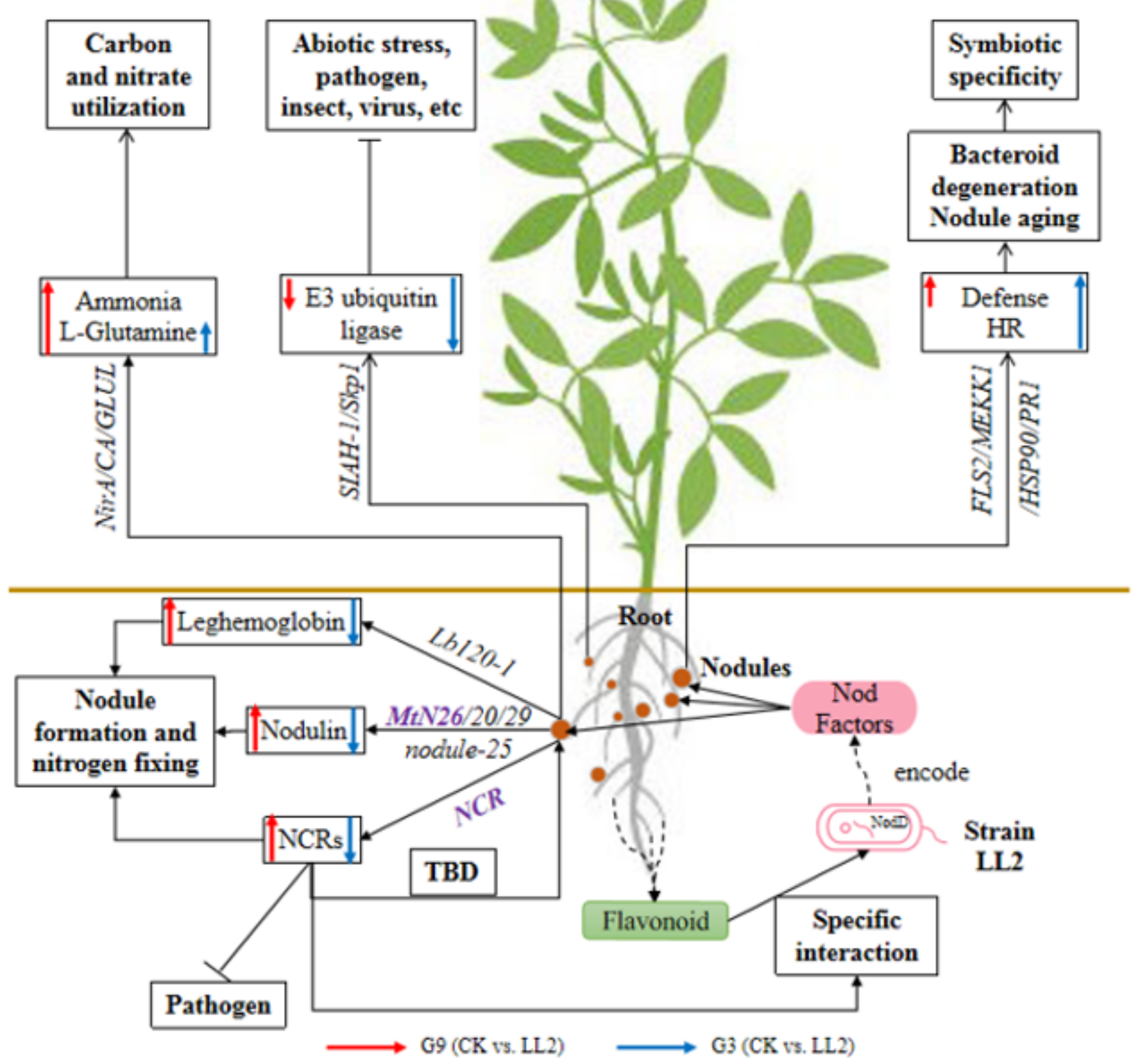

\section{Figure 11}

Proposed model of growth promotion mechanism of strain LL2 on alfalfa cultivars G9 and G3. Hub genes determining symbiotic specificity are labeled in purple. The upward and downward arrows represent upregulated and downregulated expression, respectively. The upward and downward dashed arrows indicate that most genes were upregulated and downregulated, respectively. The expression levels are showed using different arrow lengths. TBD, terminal bacteriod differentiation; PTI, PAMP-triggered immunity; ETI, effector triggered immunity; HR, hypersensitive response. 


\section{Supplementary Files}

This is a list of supplementary files associated with this preprint. Click to download.

- Additionalfile1.tif

- Additionalfile2.png

- Additionalfile3.tif

- Additionalfile4.tif

- Additionalfile5.tif

- Additionalfile6.docx

- Additionalfile7.docx

- Additionalfile8.tif

- Additionalfile9.docx 